\title{
Verification of the Climatic Features of a Regional Climate Model with BAIM
}

\author{
Kazuo MABUCHI, Yasuo SATO \\ Meteorological Research Institute, Japan Meteorological Agency, Tsukuba, Japan \\ and \\ Hideji KIDA \\ Department of Geophysics, Faculty of Science, Kyoto University, Kyoto, Japan \\ (Manuscript received 15 Septempber 2000, in revised form 27 April 2002)
}

\begin{abstract}
Verification of local climatic features produced by a regional climate model (JSM-BAIM) that includes a Biosphere-Atmosphere Interaction Model (BAIM) in the Japan Spectral Model (JSM) was performed. The data used in the verification were the results of a six-year integration calculated by the JSM-BAIM. In the time integration of the JSM-BAIM, the spectral boundary coupling (SBC) method was used. The reproducibility of horizontally distributed features, and local and seasonal changes in the principal climatic elements of the model, were investigated in finer detail than that of our previous study.

Comparisons of the model results with JMA objective analysis data were performed with respect to geopotential heights, temperatures, and winds at the $850-\mathrm{hPa}$ and $500-\mathrm{hPa}$ levels. Statistically significant differences appeared, mainly in the summer temperature field, and in the summer and the winter wind fields. It was considered that the statistically significant differences in the summer temperature field were due to the effects of land surface processes, and the summer convection process over the southern ocean area. The statistically significant differences in the wind field were mainly due to the influence of differences in topography between the regional model field and the analysis field, especially when interacting with the strong wind flow during the winter season.

Comparisons of the model results with the data of dense surface meteorological observation network (AMeDAS) were performed with respect to precipitation, surface air temperature, and radiation at the land surface over four typical climate areas in the Japanese Islands. The model reproduced reasonably well the features of the seasonal and interannual variations of each variable, in each area. There were, however, some seasonal and regional features in the differences between the model results and the AMeDAS data.

The JSM-BAIM, with the use of the spectral boundary coupling (SBC) method in a long period time integration, had sufficient accuracy for use in investigations of the interaction mechanisms between the terrestrial ecosystems and climate; temporally at least on the level of the seasonal and interannual variations, and spatially at least on the level of the climatic classification of the Japanese Islands. There is, however, the necessity for further verification using observed data, especially with respect to the near land surface air temperature in a natural vegetation environment, and the atmospheric variables over the ocean.
\end{abstract}

Corresponding author: K. Mabuchi, Meteorological Research Institute, Japan Meteorological Agency, 1-1 Nagamine, Tsukuba 305-0052, Japan.

E-mail: kmabuchi@mri-jma.go.jp

(C) 2002, Meteorological Society of Japan

\section{Introduction}

Global warming resulting from increases in greenhouse gases in the atmosphere is a very important problem. Presently, in this respect, 
the estimation of the carbon dioxide budget is of great importance. The main components that influence the carbon dioxide budget are anthropogenic emissions, atmospheric concentrations, exchanges between the atmosphere and ocean, and exchanges between the atmosphere and the terrestrial biosphere. The role of the terrestrial biosphere is the most uncertain among the main components of the carbon dioxide budget (IPCC 1996). The influence of deforestation on climate is also a very serious problem. The mechanisms of these, however, are nonlinear and complicated (Lean and Rowntree 1997). Therefore, these mechanisms have not been satisfactorily clarified as of yet. For these reasons, it is necessary to achieve a better understanding of the interaction mechanisms between the land surface ecosystem and the atmosphere.

One of the most potent methods used to study such mechanisms is a numerical simulation using a climate model. The land surface ecosystem is generally considered heterogeneous. Therefore, to treat the heterogeneity of the land surface as accurately as possible, it is desirable that climate models have a high resolution. The advantage of a regional climate model is that it can satisfy these conditions, using fewer computational resources.

The use of regional climate models for climate studies was first employed by Dickinson et al. (1989), and Giorgi (1990). Since then, there have been many studies making use of regional climate models, among them Kidson and Thompson (1998), Noguer et al. (1998), Seth and Giorgi (1998), Giorgi et al. (1999), and Small et al. (1999). To drive regional climate models, it is necessary to use a nesting technique for the regional model to incorporate boundary data. Kida et al. (1991) developed a nesting technique for the regional climate model; namely, the spectral boundary coupling (SBC) method.

The SBC is a technique used in a long period integration of a regional model to simulate regional climate. When making use of this coupling method, the regional model can simulate synoptic scale phenomena with no phase deviation from the boundary data. It can also reduce the atmospheric field error, especially around the center of the model domain (Kida et al. 1991; Sasaki et al. 1995; Sasaki et al. 2000). Therefore, using the SBC, the model can simu- late the regional climate more accurately, and a more accurate description can be gained of the interactions between the land surface ecosystem and climate. This accuracy is necessary to clarify the mechanisms of the interactions.

Recently, Mabuchi et al. (1997) developed a sophisticated land surface process model, termed the Biosphere-Atmosphere Interaction Model (BAIM). Mabuchi et al. (2000) then developed a new regional climate model that included BAIM, and clarified the relationships between climate and the carbon dioxide cycle over the Japanese Islands and surrounding area. In the six years and five months of time integration, the SBC method was used.

Regional climate models used to investigate the mechanisms of the interactions between the atmosphere and terrestrial biosphere are required to satisfy certain conditions. The models must accurately reproduce the temporal and spatial features of the principal elements that influence the heat, water, and carbon dioxide balances at the land surface through vegetation activity. In the study of Mabuchi et al. (2000), analyses concerning the area mean values of these elements of the overall model domain, and those of the Japanese Islands area were carried out. The main focus of the study was on the interactions between the carbon dioxide cycle and regional climate. In the present study, the reproducibility of the features of the horizontal distributions, along with the features of the local and seasonal changes of the model elements will be discussed in finer detail than that in Mabuchi et al. (2000). Another purpose of the present study is to verify the performance of the results of the control simulation of this model, providing material for future study.

Section 2 briefly reviews the model structure and experimental design of the study, while Section 3 presents several results. Summary and discussion are given in Section 4.

\section{Model description and experimental design}

The regional climate model used in the present study is the Japan Spectral Model (JSM), including the Biosphere-Atmosphere Interaction Model (BAIM) (Mabuchi et al. 1997; Mabuchi et al. 2000). Hereafter, this regional climate model is referred to as the JSM-BAIM. In 
this section, the model structure and experimental design will be briefly reviewed. For further details, the reader should refer to Mabuchi et al. (2000).

The model employs sigma coordinates, with 23 levels in the vertical. The model has a regular $129 \times 129$ square transform grid on a polar stereographic projection plane, which translates to a horizontal resolution of $30 \mathrm{~km}$ at $60^{\circ} \mathrm{N}$. The basic equations adopted in the model are the primitive equations. The prognostic atmospheric variables are temperature, specific humidity, zonal and meridional components of the wind, carbon dioxide concentration, and surface pressure. The model includes the shortwave and the long-wave radiation processes (Sugi et al. 1990; Lacis and Hansen 1974). Precipitation is governed by three processes; that is, large-scale condensation, moist convective adjustment, and the evaporation of raindrops. Vertical diffusion is calculated by the level 2 turbulent closure model, proposed by Mellor and Yamada (1974).

Land surface processes are calculated within the BAIM. The BAIM has two vegetation layers and three soil layers, and predicts the temperature and stored moisture for each layer. In the presence of snow cover, the snow layer is divided into a maximum of three layers, with the temperature and amount of snow and water stored in each layer being predicted. Photosynthesis processes for $\mathrm{C}_{3}$ and $\mathrm{C}_{4}$ plants are adopted in the model. The model can also predict the ground accumulation and melting of snow, and the freezing and melting of water within the soil. The type of vegetation at each model grid point is specified according to actual vegetation data (see Mabuchi et al. 2000).

Two boundary coupling methods are simultaneously used during the time integrations. One is the time-dependent lateral boundary coupling (LBC) which uses the conventional boundary relaxation as originally proposed by Davies (1976). The other is the spectral boundary coupling (SBC) after Kida et al. (1991). Meteorological boundary condition data are created from global objective analysis data of the Japan Meteorological Agency (JMA). The grid size of the analysis data is $2.5^{\circ}$ for the period from May 1983 through February 1988, and $1.875^{\circ}$ since March 1988. Twelve-hour interval analysis data (00 and 12 UTC of each day) are interpolated onto the JSM-BAIM grid, and then used for the initial conditions, lateral boundary conditions, and spectral boundary conditions of the model. The boundary conditions for carbon dioxide concentrations are taken from the $8 \mathrm{~km}$-tropopause data given in Table 2 of Nakazawa et al. (1993). For the SBC of this experiment, the spectral boundary wave-number is set to 3 . The SBC is applied to the temperature, and the zonal and meridional wind component fields at each level above the 0.53 sigma level.

The sea surface temperature and sea ice values are taken from the GISST2.2 dataset (Rayner et al. 1996). The monthly values of these data are assigned to each JSM-BAIM ocean-area grid point. The carbon dioxide fluxes between the sea surface and the atmosphere are prescribed through estimated values taken from data observed by the JMA (Japan Meteorological Agency 1994).

To estimate the initial values of soil wetness, including the ice content in the soil and soil temperature, ten time integrations over the one year period from 12 UTC 31 July 1985, to 12 UTC 31 July 1986, were carried out. In these pre-runs, the last values in the soil predicted by the previous one-year integration were used for the initial values of the next one-year integration. Using the final values in the soil obtained from the ten yearly pre-runs as initial conditions, the experimental time integration was started at 12 UTC, 31 July 1985, and continued until 12 UTC, 31 December 1991, for a total model time of six years and five months.

\section{Results}

Experimental results for the six-year period from 1 January 1986 to 31 December 1991 were examined. Figure 1 shows the domain of the JSM-BAIM and the areas examined. The topographic features of the model are also indicated. Area A covers the entire domain of the JSM-BAIM, except for the model lateral boundary areas. The region of the Japanese Islands is divided into four areas (Areas B, C, D, and $\mathrm{E}$ ) according to regional features of climate.

\subsection{Comparison of model atmospheric variables with analysis data}

Figures 2 and 3 show the atmospheric results calculated by the model (left-hand side of fig- 


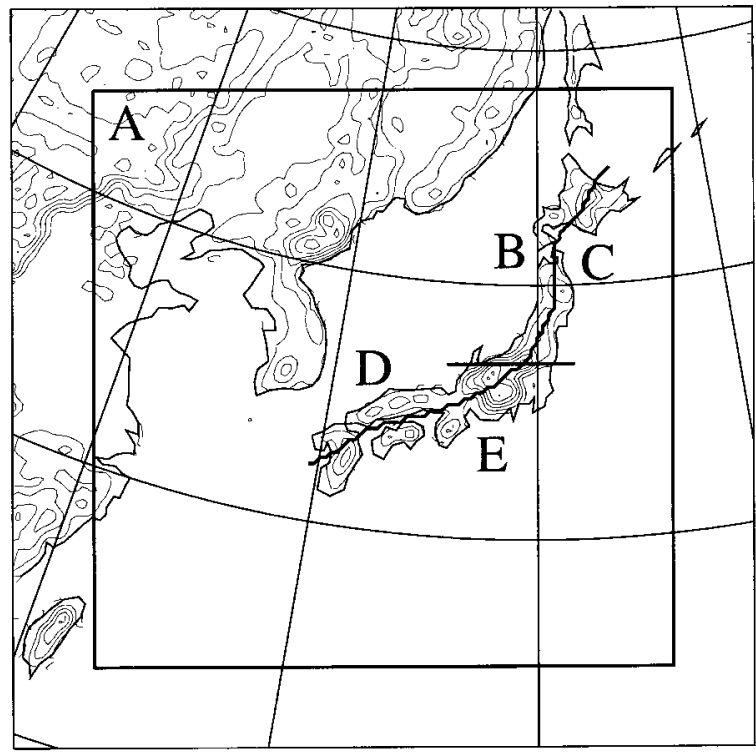

Fig. 1. The domain of the JSM-BAIM and the areas examined (A, B, C, D, E). Contour interval of the topography is $300 \mathrm{~m}$.

ures) with the differences between the model results and analysis data (right-hand side of figures; model-analysis) at the $850-\mathrm{hPa}$ level. The analysis data (hereafter referred to as JANAL) are the regional objective analysis data corresponding to the JSM-BAIM domain, interpolated from the JMA's global objective analysis data. Figure 2 shows the six-year mean summer season values (three-month mean of June, July, and August: JJA) over Area A in Fig. 1. Figure 3 shows the six-year mean winter season values (three-month mean of December, January, and February: DJF) over Area A. The base data are the data at 12 UTC on each day, corresponding to 20 to 21 o'clock in local time of this model region. In each side of the figure, the top portion indicates geopotential height, the middle temperature, and the bottom wind vectors. Solid-shaded areas are the areas where the heights of the 850-hPa level are lower than those of the corresponding JSM-BAIM grid topography. In the right-hand figures that indicate differences, the lightly shaded areas are where the model values are greater than the JANAL. The densely shaded areas are where the Student's $t$-test values indicate statistically significant (at 95\% level; $t$ value of 2.228) dif- ferences. Concerning the wind, the differences in wind vectors were calculated from the differences in the $u$ and $v$ wind components between the model and the JANAL. The statistically significant difference areas of the wind vectors, therefore, indicate statistically significant difference areas in each wind component, or in both.

In the summer season (Fig. 2), the absolute values of the difference in the geopotential height between the model results and the JANAL are less than ten meters. Statistically significant differences do not exist. In the temperature field, the model results indicate statistically significant lower values than the JANAL around the high mountain areas, and over the ocean area in the southern part of the model domain. In the wind field, there are significant differences around mountains, and over the eastern part of the Sea of Japan. The areas of significant difference, however, are not large in the wind field.

In the winter season (Fig. 3), although the pattern of difference is more complicated than that during the summer season, the degree of the geopotential height difference is almost the same as that found in the summer season. In the same manner as in the summer season, statistically significant differences do not exist, except for the small area around the northwestern high mountain area. In the temperature field, the pattern of difference is more complicated than that in the summer season. The statistically significant difference area is, however, much smaller than that found in the summer season. In the winter wind field, the statistically significant difference areas around mountain regions are larger than those in the summer season.

Figure 4 shows the comparison of the model results with the JANAL at the $500-\mathrm{hPa}$ level. Only the figures for the difference are shown. The left-hand side of the figure indicates the results for the summer season (JJA), and the right-hand side the results for the winter season (DJF). The base data are the data at 12 UTC on each day. The top portion indicates geopotential height, the middle temperature, and the bottom wind vectors. The lightly shaded areas are where the model values are greater than those of the JANAL. The densely shaded areas are where the Student's $t$-test values in- 


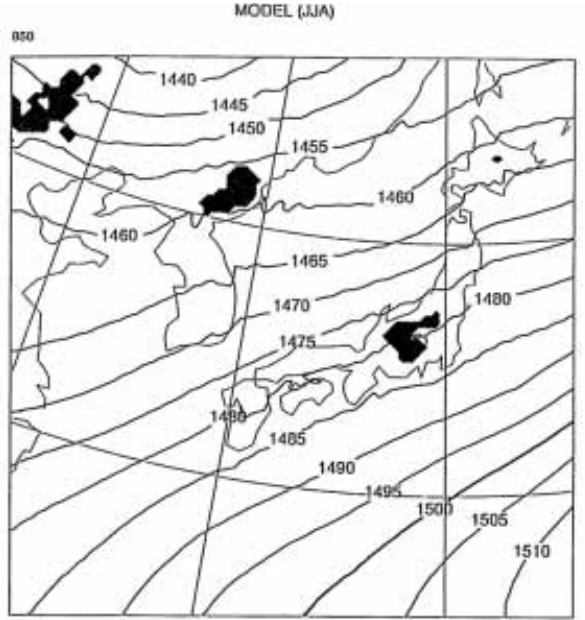

$\mathrm{GPH}(\mathrm{m})$

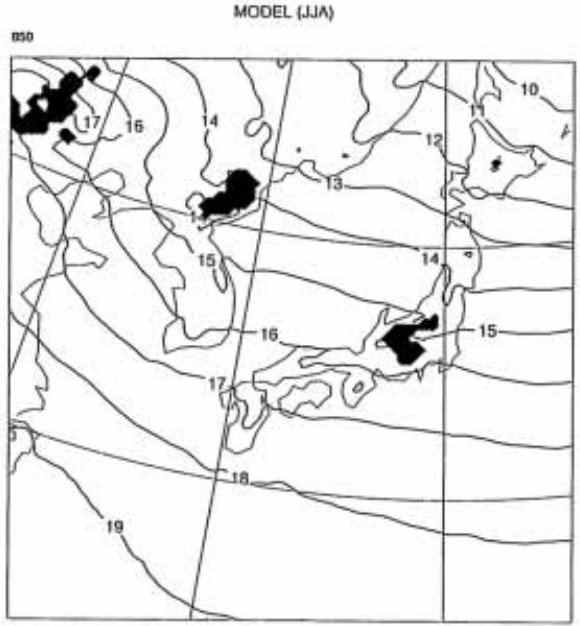

T (C)

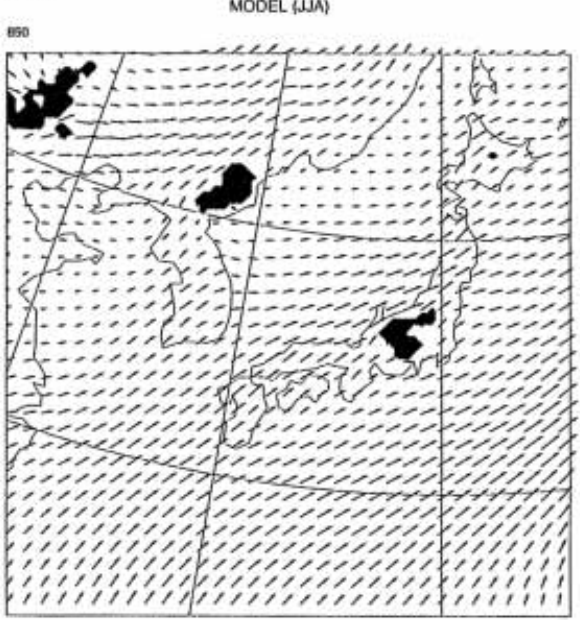

$-5 \mathrm{~m} / \mathrm{s}$

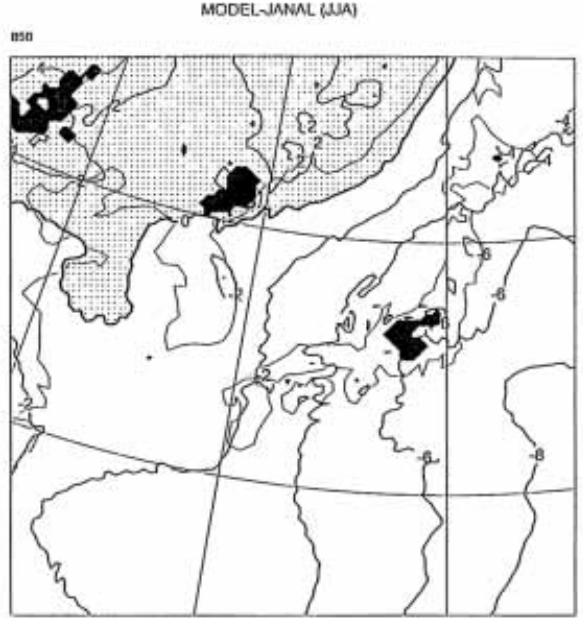

GPH (m)

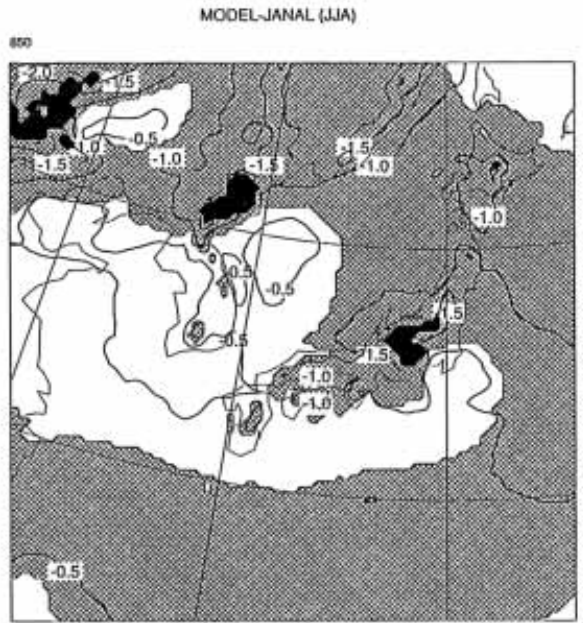

$T$ (C)

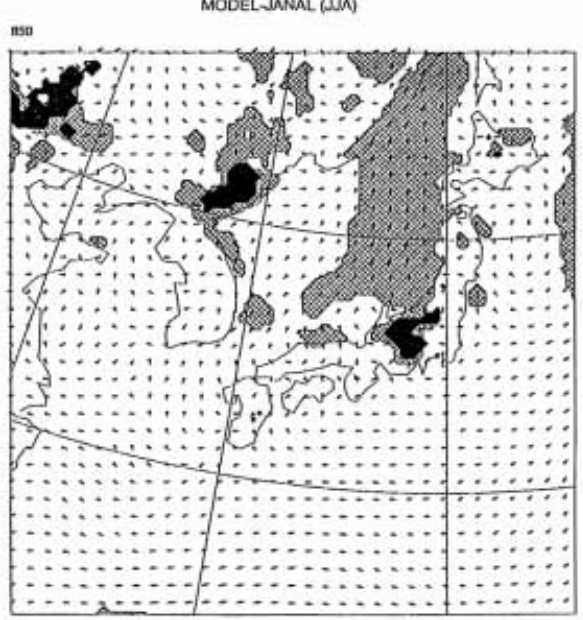

$-5 \mathrm{~m} / \mathrm{s}$

Fig. 2. The 850-hPa atmospheric results calculated by the model (left-hand side), and the differences between model results and analysis data (right-hand side). The results are for the six-year mean summer season (JJA) values. The top panel is geopotential height $(\mathrm{m})$, the middle temperature $\left({ }^{\circ} \mathrm{C}\right)$, and the bottom wind vectors $\left(\mathrm{m} \mathrm{s}^{-1}\right)$. 

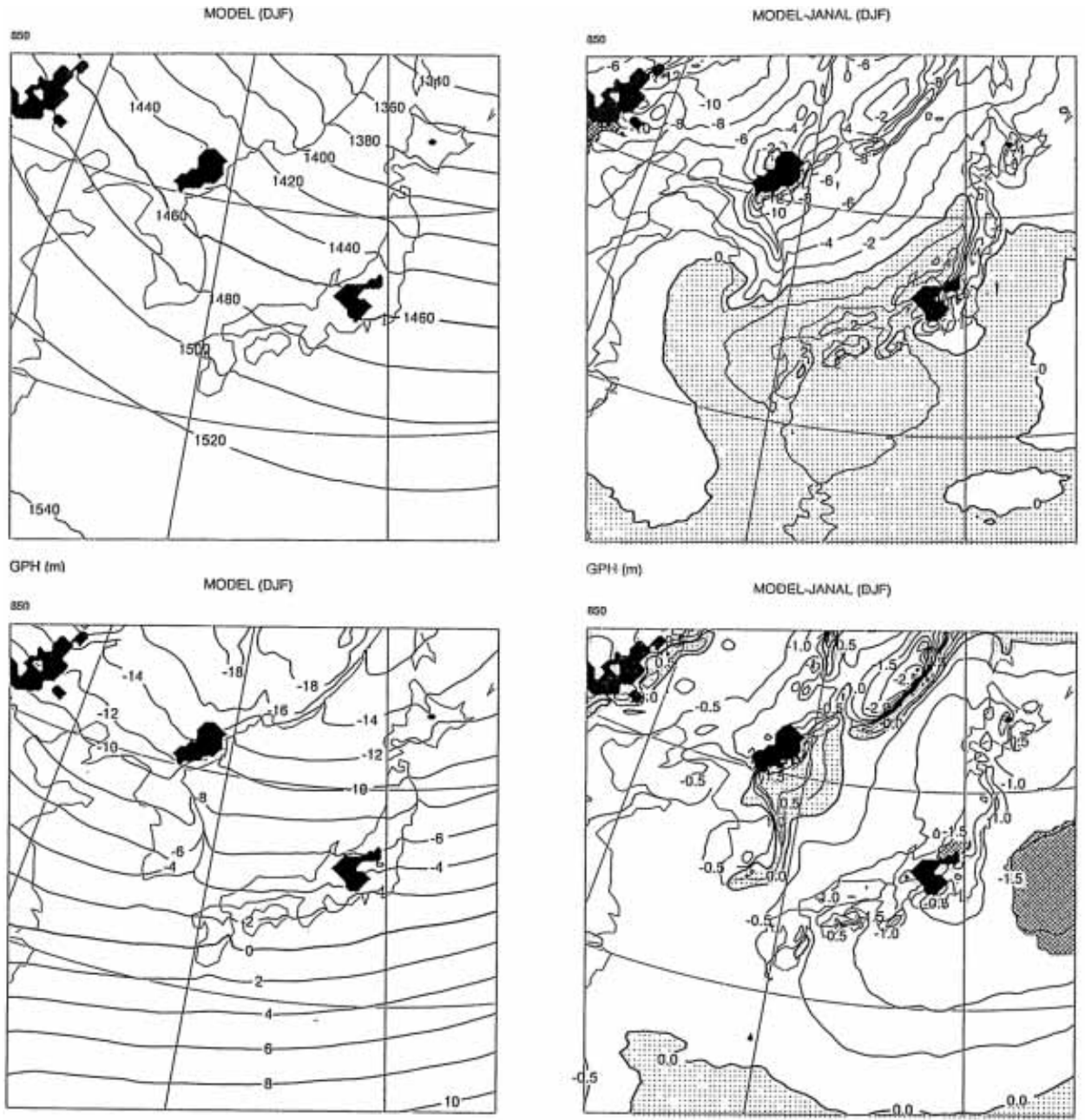

GPH (m) MOOEL-JANAL, (DUF)
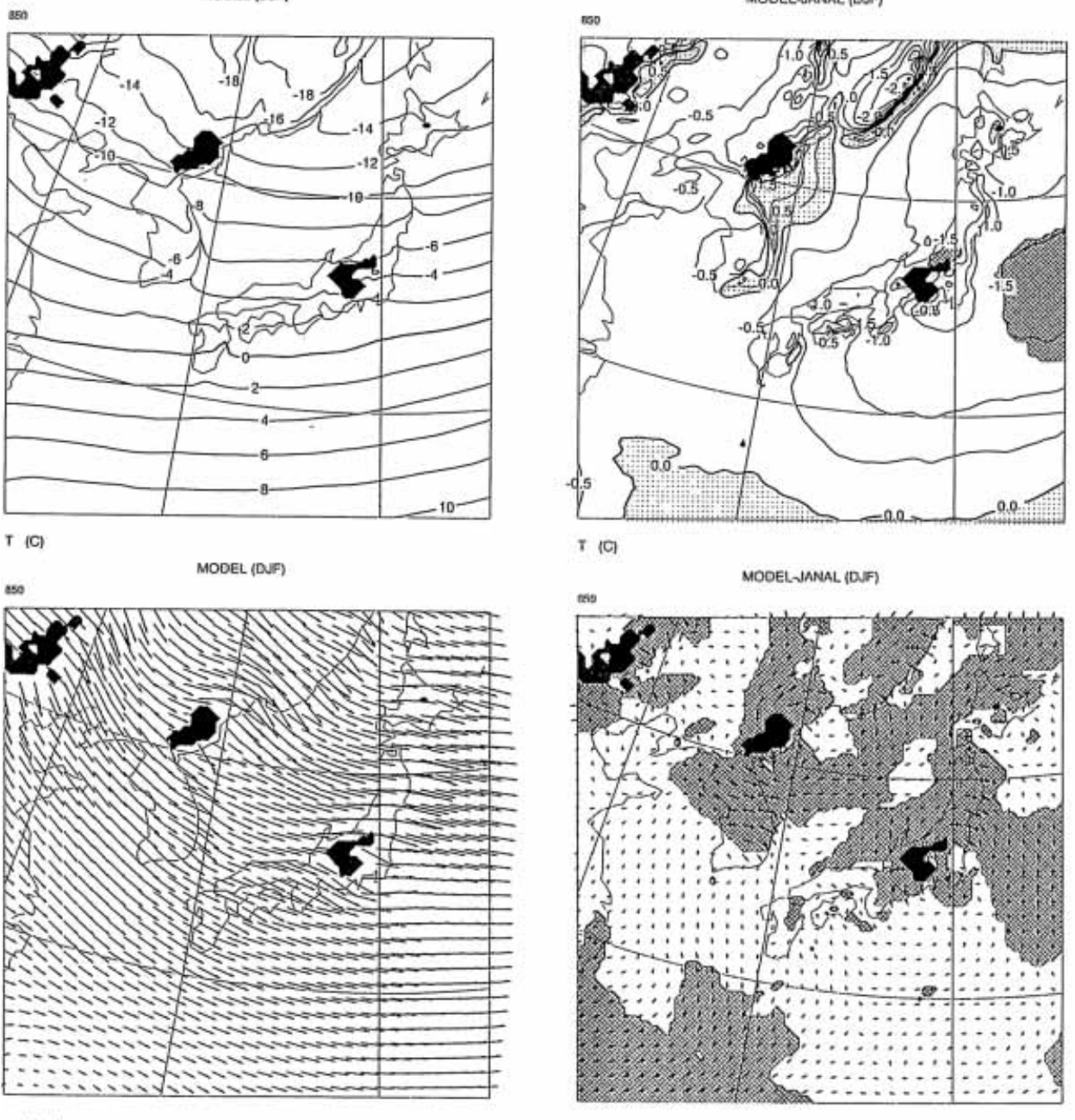

$-5 \mathrm{~m} / \mathrm{s}$

Fig. 3. As in Fig. 2, except for the six-year mean winter season (DJF) values. 

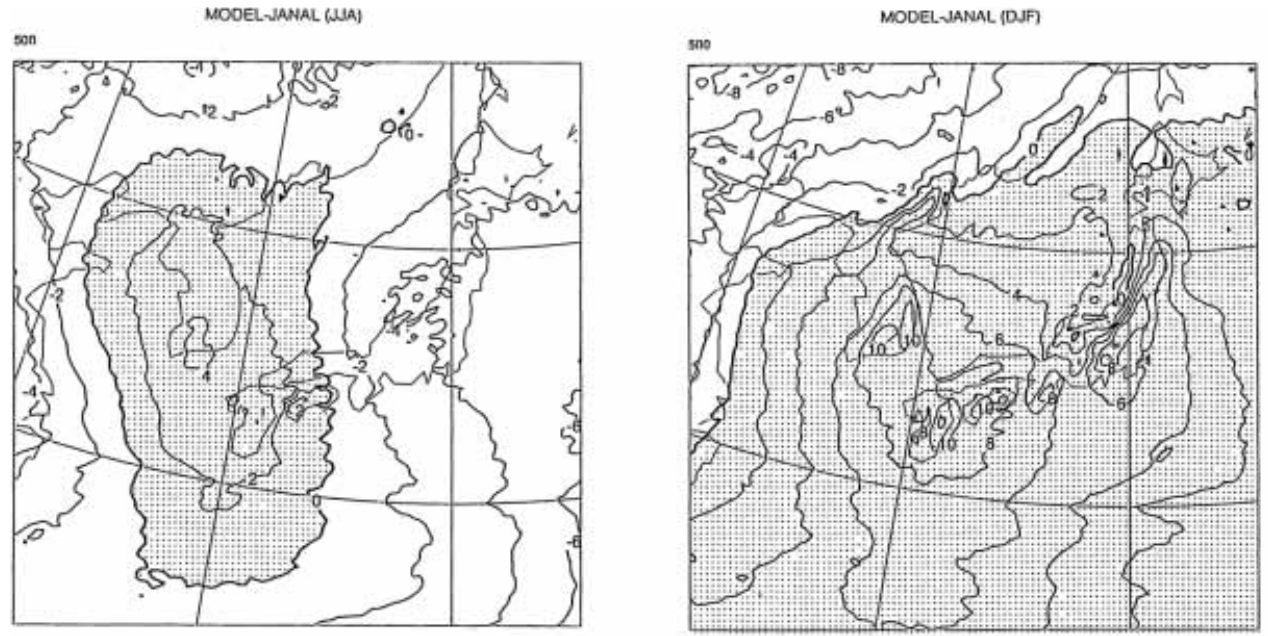

GPH (m) MODEL.JANAL (HAA)

500

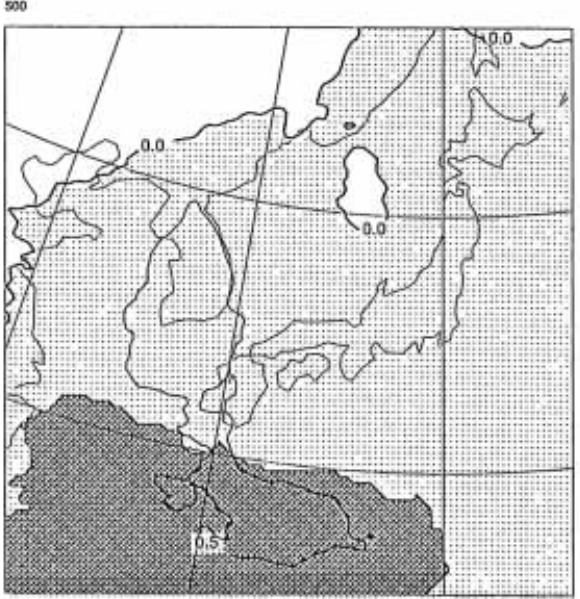

$\mathrm{GPH}(\mathrm{m})$

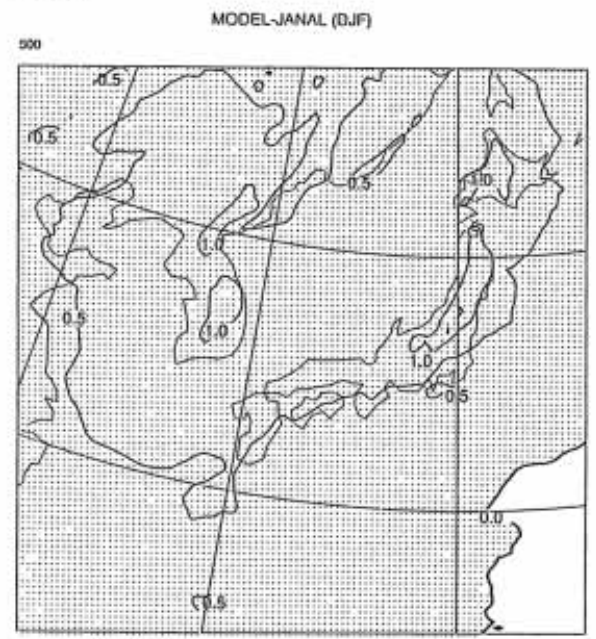

T (C)

MOOEL.JMNAL (JMA)

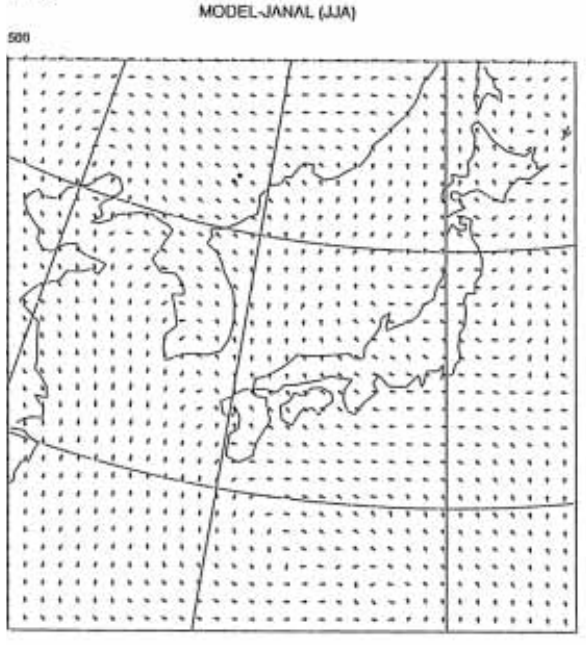

$T$ (C)

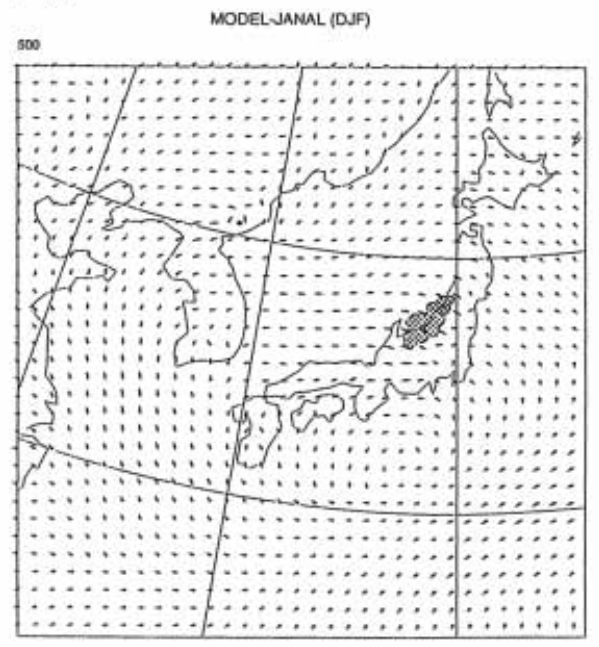

$-5 \mathrm{~m} / \mathrm{s}$

Fig. 4. The comparison of model results with the JANAL at the 500-hPa level. The left-hand figures indicate the differences in the summer season (JJA), and the right-hand figures those in the winter season (DJF) over Area A. The top panels indicate geopotential height $(\mathrm{m})$, the middle temperature $\left({ }^{\circ} \mathrm{C}\right)$, and the bottom wind vectors $\left(\mathrm{m} \mathrm{s}^{-1}\right)$. 
dicate statistically significant (at 95\% level; $t$ value of 2.228) differences.

Over the summer season, there is an area of significant difference in temperatures in the southern part of the model domain. In the winter season, except for a small area of significant difference in the wind field over central Japan, no statistically significant differences exist in each data field. The areas of statistically significant difference at the $500-\mathrm{hPa}$ level are smaller than those at the $850-\mathrm{hPa}$ level.

There are some discrepancies between the results of the JSM-BAIM and the JANAL in each data field for each season. Statistically significant differences, however, appear mainly in the summer temperature field and in the summer and the winter wind fields. The boundary data for the JSM-BAIM are taken from the JANAL. Therefore, these significant differences are due to the differences in resolution and in the physical processes between the JSM-BAIM field and the JANAL field.

In Fig. 2, the model temperatures were shown to be significantly lower than the JANAL temperatures around the high mountain area in the northern part of the model domain. The geopotential heights of the model are higher than those of the JANAL over the Asian Continent (top panel). The values of the temperature differences, however, are greater than those estimated from the differences in geopotential heights. Figure 5 shows the elevation differences in the topography between the JSMBAIM field and the JANAL field. The elevations of the JSM-BAIM topography are higher than those of the JANAL field in the mountainous regions. The temperature of the JSMBAIM at the 850 -hPa level is strongly influenced by the temperature at the near land surface in the high mountain regions. Potential reasons that result in low near land surface air temperature are reduced radiation at the land surface, and an excess of the evapotranspiration from the land surface that work to suppress the increase of the land surface temperature.

Figure 6 shows the six-year mean summer cloudiness calculated by the model. The values of model cloudiness over the Asian Continent are relatively small at all levels. Moreover, the radiation process employed in the JSM-BAIM has a tendency to estimate larger values of

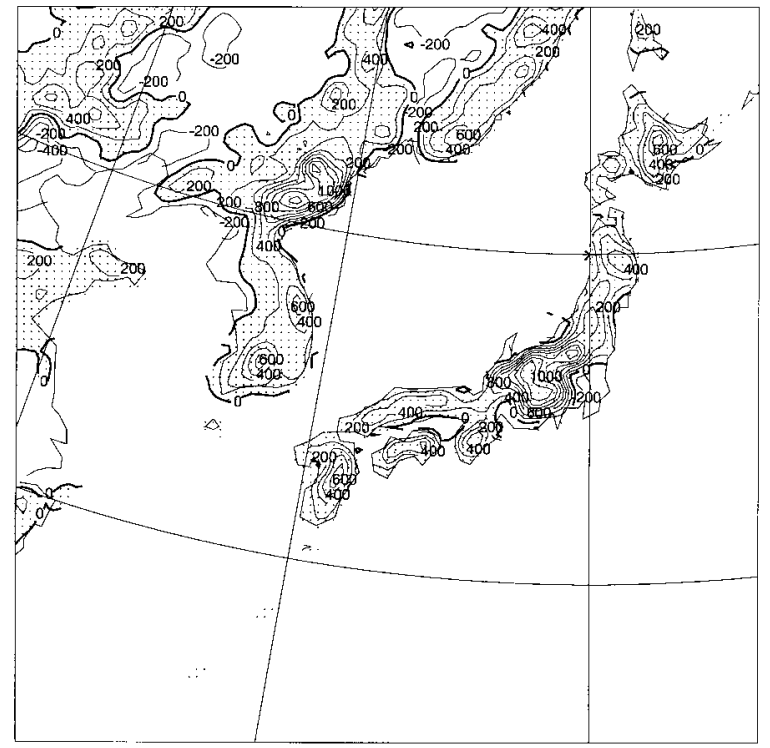

Fig. 5. The difference in the topography elevations between the JSM-BAIM field and the JANAL field (grid size of $1.875^{\circ}$ ) in Area A. The contour interval is $200 \mathrm{~m}$. The areas where the topography of the JSM-BAIM is higher than that of the JANAL field are shaded.

downward short-wave radiation than those observed for clear sky conditions (Japan Meteorological Agency 1996). Therefore, it is considered that the radiation values at the land surface in the JSM-BAIM are not the main reason for the significant low temperatures, especially over the Asia Continent.

Figure 7 shows the comparison of the summer season temperature minus dew point (T-Td) values of the model with those of the JANAL for each year. The lightly shaded areas indicate model values greater than the JANAL. Solid-shaded areas in the 850 -hPa level panels are the areas where the heights of the $850-\mathrm{hPa}$ level are lower than those of the corresponding JSM-BAIM grid topography. At the $850-\mathrm{hPa}$ level (top panel), the model values of T-Td around high mountain areas are systematically smaller than the JANAL. Namely, the model humidity in these areas is higher than that of the JANAL. It is considered that the model evapotranspiration from the land surface is large and the increase of the land surface temperature is suppressed. There is the possibility that these low model land surface temper- 


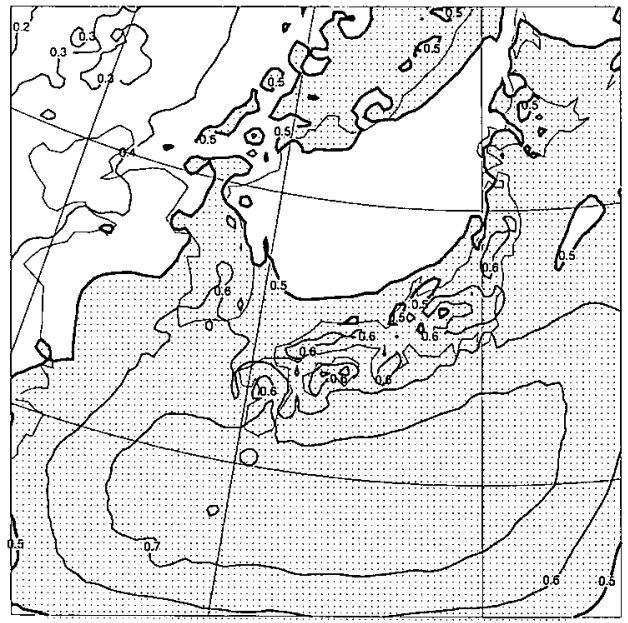

CLOUD (DAILY MEAN)

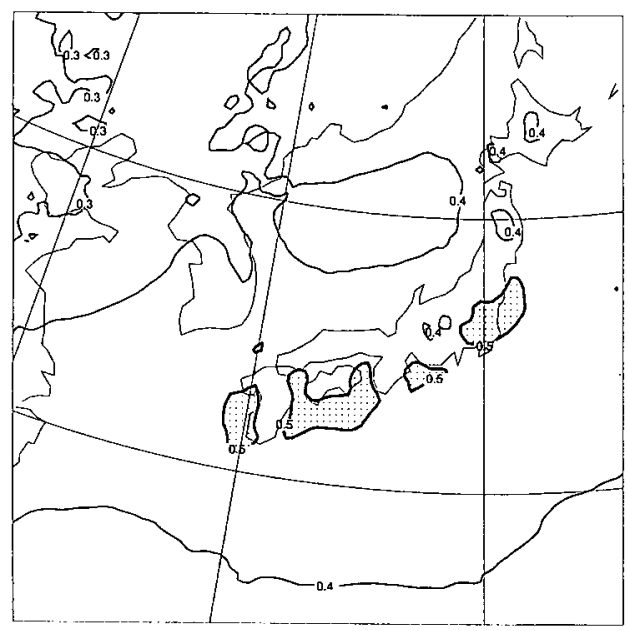

CLOUD (DAILY MEAN)

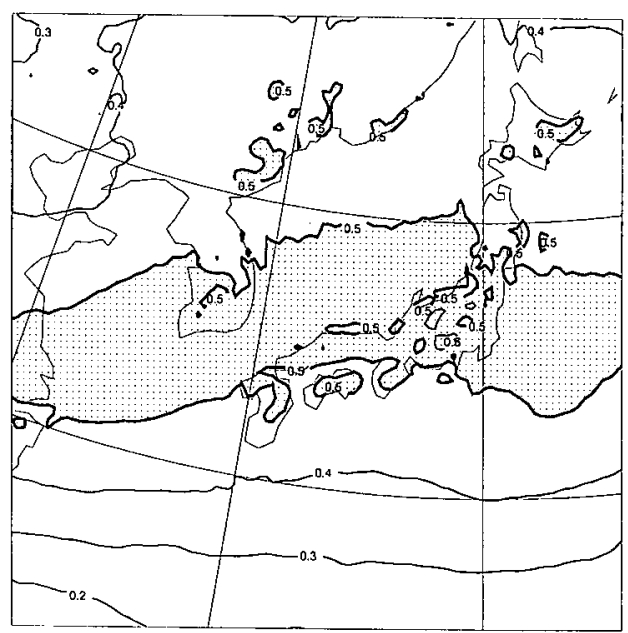

CLOUD (DAILY MEAN) atures result in the lower $850-\mathrm{hPa}$ level model temperatures around high mountain areas than those of the JANAL.

There is the necessity of further discussion concerning the accuracy of the near land surface air temperatures in the model. The global model used at the production step of the JMA's global objective analysis data has the tendency to calculate higher near land surface air temperatures than those observed. It is thought that the cause of this is related to the land surface processes in the global model (Japan Meteorological Agency 1996). The JANAL data are influenced by this tendency of the global model. In the summer season, the control of transpiration by vegetation activity at the land surface is very important. The ratio of transpiration by vegetation to the evapotranspiration from the land surface is large in the summer season (see Fig. 11 in Mabuchi et al. 2000). In the JSMBAIM, vegetation covers the land surface. In particular, the model grid points in the mountain areas are assigned the vegetation type of natural forest. Generally, the observed result in a natural forest vegetation is not reflected in the analysis data. Wide areas of observed data for the natural forest environment are necessary for a more accurate verification of the near land surface air temperature in the model.

Over the southern part of the Japanese Islands, there are large values of cloudiness. Therefore, there is the possibility that the reduced radiation in the model results in the significant low model temperatures in that area. The verification of surface air temperature of the model over the Japanese Islands will be discussed in more detail in the next section.

Fig. 6. The cloudiness (daily mean) values calculated by the model. The six-year mean summer season (JJA) values over Area A are indicated. The top panel indicates the low atmospheric level cloudiness (below the 0.86 sigma level), the middle panel the middle atmospheric level cloudiness (the $0.82 \sim$ 0.53 sigma levels), and the bottom the high atmospheric level cloudiness (above the 0.47 sigma level). The areas where the cloudiness values are greater than 0.5 are shaded. 


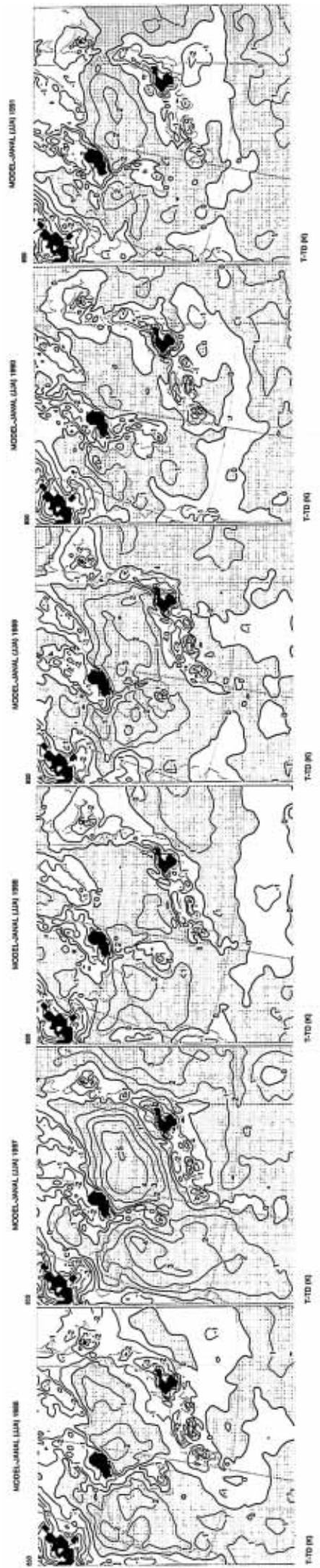

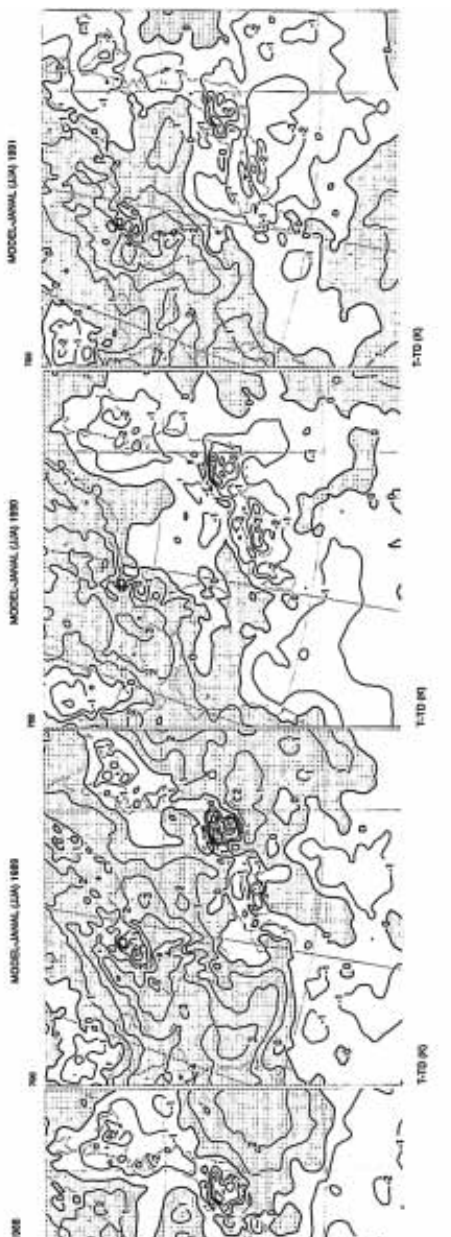

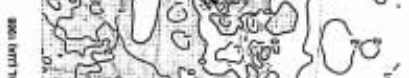

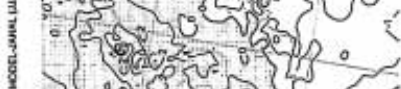

त. 58 - 3$\}\}$ [3] - calr a cant

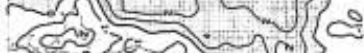
s. ( 50 \%

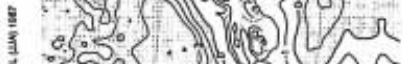
E $30 \mathrm{~s}$. (3) $10.3(0.0)>3)$

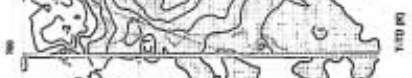
उल्धि - -7 (1)

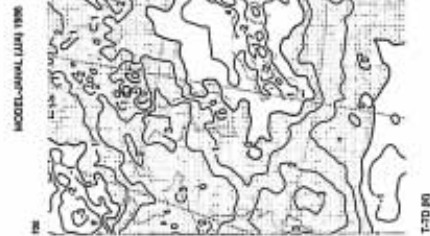

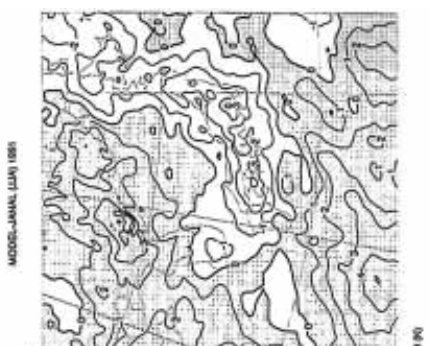

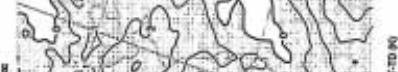

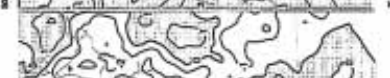

1. 0 - 200

(i) 3 . nु?

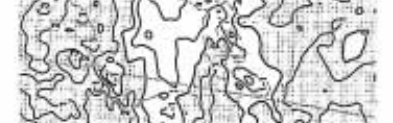

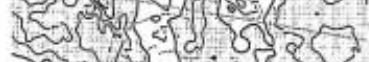
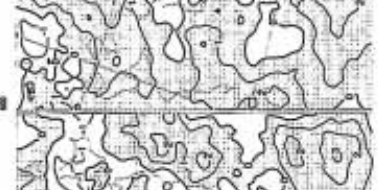

$(1,2000)$

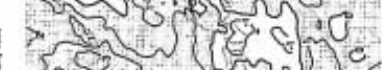

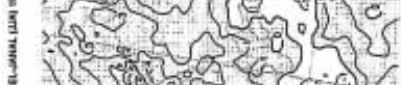

S) 20500

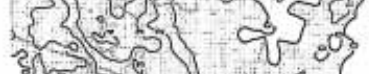

से क $x^{\circ}$.

3)

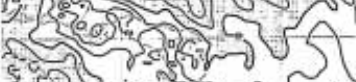

- Sun aliz: $0^{\circ}$

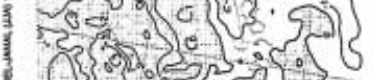

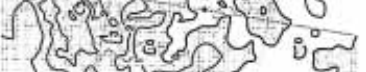
कीजि QS 5 - म2

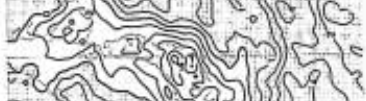

- aे 0 o - 3 s

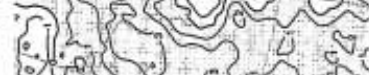
injol ef $0^{t}=$ - की (3) (u) हैं

$13(0)$ (a)

1 \%०तिए

(3) D.

8

욜

ซึ

过

बै

它客兽

度密

○

:

पै

幽

要通

考完

5 दे द्व

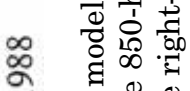

ऽ द्व 0

돞

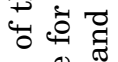

बิ

की

ส สี.

용

다

$\stackrel{2}{\circ}$

㟧㟧

节离兽

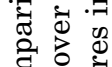

है चै

政

E

. ซี हี

so 
In Fig. 2, it was shown that the model summer temperatures at the 850 -hPa level were significantly lower than the JANAL over the ocean area in the southern part of the model domain. In Fig. 4, the model summer temperatures at the $500-\mathrm{hPa}$ level were found to be significantly higher than the JANAL over the same area. Although the investigation of the mechanism for the difference between the model and the JANAL is difficult, because the analysis data used in the investigation are limited, the general concept for the mechanism of the temperature differences over the area is considered in the following.

In Fig. 6, the model values of the atmospheric low-level cloudiness were found to be large over the ocean area in the southern part of the model domain. Figure 8 shows the summer season precipitation calculated by the model. The precipitation for each year over Area A are indicated. In 1988 and 1989, the values of precipitation over the ocean area in the southern part of the model domain are especially large. In Fig. 7, although the interannual variations and area variation were large, the difference of T-Td between the model and JANAL indicated a tendency of higher model humidity values than the JANAL at low atmospheric levels over the southern ocean area. In 1988 and 1989 in particular, the model humidity values over this area have a tendency to be higher than those of the JANAL at all levels. Although the model cloudiness can not be compared with the JANAL, since JANAL cloudiness data do not exist, there is the possibility that the model ocean area convective activity in the summer over the southern part of the model domain is more active than that in the JANAL field, and the model cloudiness values over the area are larger than those that would have occurred in the JANAL field.

In general, short-wave radiational heating and long-wave radiational cooling occur at the cloud tops, while long-wave radiational heating occurs at the bottom of clouds. The existence of clouds induces the suppression of short-wave radiational heating in the atmospheric layer under the cloud by the umbrella effect. In the vertical profile of the summer cloudiness calculated by the model, averaged over the southern ocean area (figure not shown), the values of cloudiness at the low atmospheric levels (below the $700-\mathrm{hPa}$ level) and at the high atmospheric levels (around the $350-\mathrm{hPa}$ level), are especially large. In the model, relatively strong cooling by vertical diffusion occurs from the $900-\mathrm{hPa}$ level to the $800-\mathrm{hPa}$ level. It is considered that the total heat balance by radiation effects related to clouds, influences the cooling at that level. Due to this effect, the model temperatures at the $850-\mathrm{hPa}$ level are lower than the JANAL temperatures over the ocean area in the southern part of the model domain.

In the model, short-wave radiational heating and long-wave radiational cooling are strong at the $350-\mathrm{hPa}$ level and the adjacent levels. These heating rates are related to the upper cloud at the $350-\mathrm{hPa}$ level and the nearby levels. The short-wave radiation can penetrate into the cloud layer by forward scattering. Therefore, while the cooling by long-wave radiation occurs mainly at the top layer of the upper cloud, heating by the short-wave radiation occurs not only at the top but also within the upper cloud layer. The temperatures at the $500-\mathrm{hPa}$ level are influenced by the heat balance connected with the radiation at the bottom layer of the upper clouds. Therefore, there is the possibility that the difference between the model $500-\mathrm{hPa}$ temperature and that of the JANAL is related to the difference in the heat balance by radiation effects connected with the upper cloud.

In Fig. 8, as already mentioned, the values of model precipitation over the ocean area in the southern part of the model domain are large, especially in 1988 and 1989. In these years, the model humidity values over this area have a tendency to be higher than those of the JANAL, not only at the 850 and $700-\mathrm{hPa}$ levels, but also at the $500-\mathrm{hPa}$ level. Therefore, another possibility is that the heating by the condensation of water vapor related to precipitation events influences the model temperatures in the middle and low atmospheric layers. This, in turn, influences the temperature differences between the model and the JANAL, at the 500-hPa level.

The observed data over the ocean area are limited. Therefore, the differences in resolution and physical process between the JSM-BAIM field and the JANAL field directly result in the temperature difference between the model and the JANAL. From the results in this paper, it is difficult to decide whether or not the JSM- 

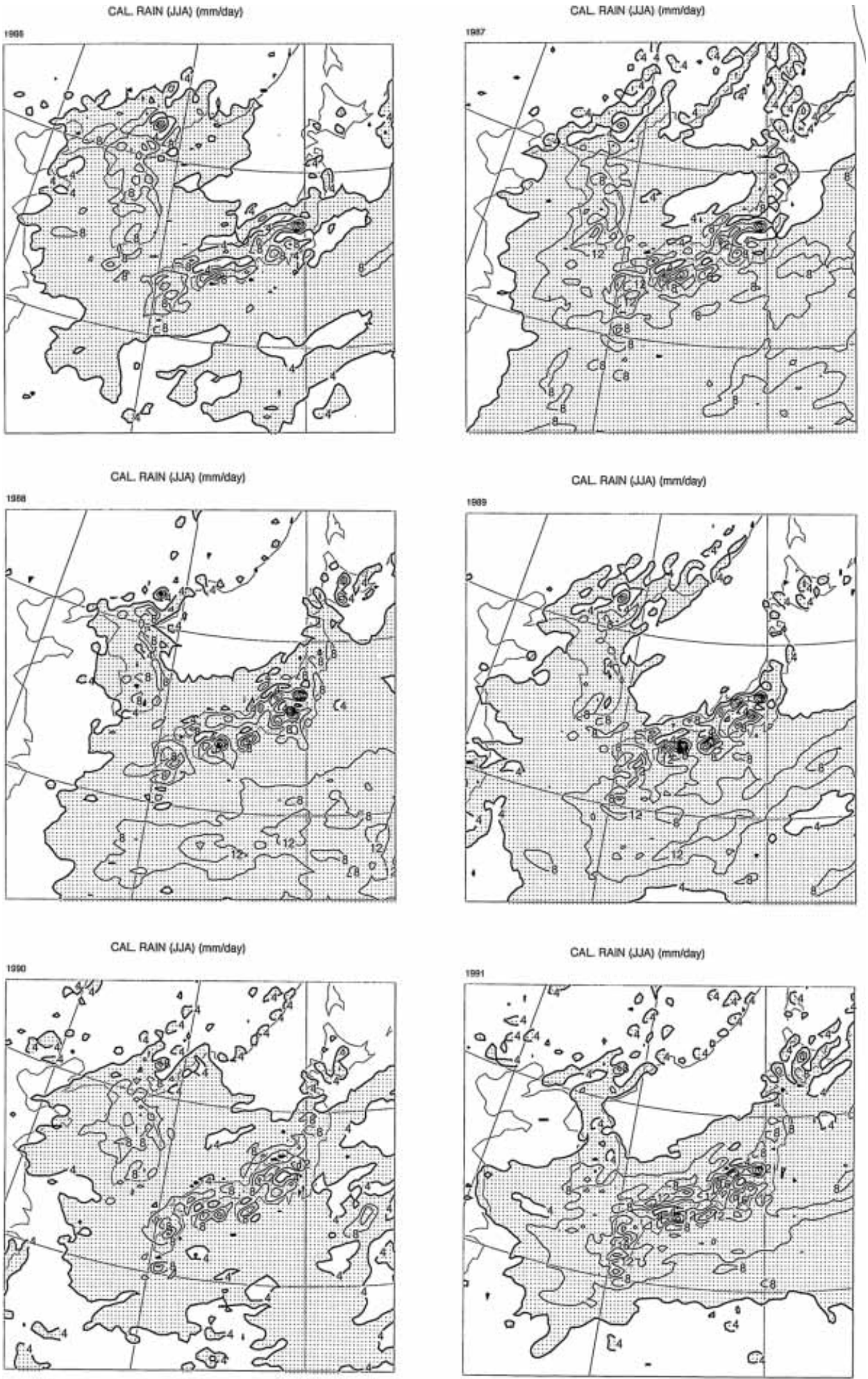

Fig. 8. The precipitation $\left(\mathrm{mm} \mathrm{day}^{-1}\right)$ calculated by the model. The values are for the summer season (JJA) over Area A in each year. The top panels indicate 1986 (left-hand side) and 1987 (right-hand side), the middle 1988 (left) and 1989 (right), and the bottom 1990 (left) and 1991 (right). The areas where the precipitation is greater than $4 \mathrm{~mm} \mathrm{day}^{-1}$ are shaded. 
BAIM results over ocean area are more realistic than the JANAL. The necessity for the verification of the model using more data observed over the ocean area still remains.

It is considered that the statistically significant differences found in the wind field are mainly due to the influence of the difference in topography between the model field and the JANAL field. The effects of the differences in topography include not only that of elevation, but also the effects of roughness and other physical elements at the land surface. The areas of statistically significant differences of wind exist mainly at the $850-\mathrm{hPa}$ level. Higher model topography elevations than those of the JANAL field exist in the northwestern model region, the coastal areas of the Korea Peninsula and the Asian Continent, and the Japanese Islands (see Fig. 5). In the summer (Fig. 2), the southwesterly seasonal wind is influenced by these higher elevations, and significant differences exist near the high mountain area. It is considered that the cause of the significant differences over the Sea of Japan is also due to the effect of the higher elevations of the Japanese Islands on the southwesterly seasonal wind. In the winter (Fig. 3), the wind field calculated by the model indicates a strong northwesterly wind, with deviations and speed changes of the wind vectors around the higher elevations of the model. A significant difference also exists in the southwestern boundary region of the model. Although the cause of this significant difference is not clear, it is inferred that it may be the total effect of the differences in the topography and geopotential heights between the model and the JANAL.

The JANAL data were interpolated from the JMA's global objective analysis data. The global objective analysis data were influenced by resolution and the characteristics of the global model used at the production step of the global objective analysis data. The resolution of the meteorological data and that of the topography of the JSM-BAIM field are finer than those of the global models. In Fig. 5, it can be seen that the elevation of the topography of the JSMBAIM field is higher than that of the JANAL field in the mountain areas. The topographic influence is greater in the winter season than in the summer season. The reason for this is the atmospheric circulation over the model domain during the winter season is generally stronger than that found in the summer season. In the winter season, strong monsoon winds from the Eurasian Continent to the Pacific Ocean are generated in this model region. The topography of the JSM-BAIM field is more realistic than that of the JANAL field. Therefore, it is considered that the wind field calculated by the JSMBAIM results in a more realistic pattern than that of the JANAL.

\subsection{Comparison of model results with AMeDAS data}

Figures 9 through 15 show the comparisons of the model results with the data observed by the Automated Meteorological Data Acquisition System (AMeDAS). The AMeDAS is an automatic meteorological observing system set up throughout Japan. The precipitation is observed at about 1300 points that are distributed with an average interval of $17 \mathrm{~km}$, while the temperature and duration of sunshine are recorded at about 900 points. For the present study, the region of the Japanese Islands was divided into four areas (Areas B, C, D, and E, see Fig. 1) according to regional features of climate, and values of the monthly area means of the meteorological variables in each area were examined. The base data are the daily total, or daily mean data of the variables.

Figures 9 and 10 show the comparisons of precipitation. In Fig. 9, the temporal distributions of the comparison of monthly mean precipitation in each area are shown. The bottom panel (ALL) in the figure shows the comparison of the four-area mean, that is, the mean over the Japanese Islands. It is clear that the seasonal and interannual variations in the southern part of the Japanese Islands (Areas D and E) are larger than those in the northern part (Areas B and C). Although the model results are about $0.5 \mathrm{~mm} \mathrm{day}^{-1}$ greater than the AMeDAS data on the four-area average in six-year mean, the correlation coefficients indicate large values for all areas. It is concluded that the model can reproduce the features of the seasonal and interannual variations of precipitation in each area.

Figure 10 shows the results of the verification of the monthly mean precipitation performed for each month. The solid lines (and circles) indicate the correlation coefficients as- 

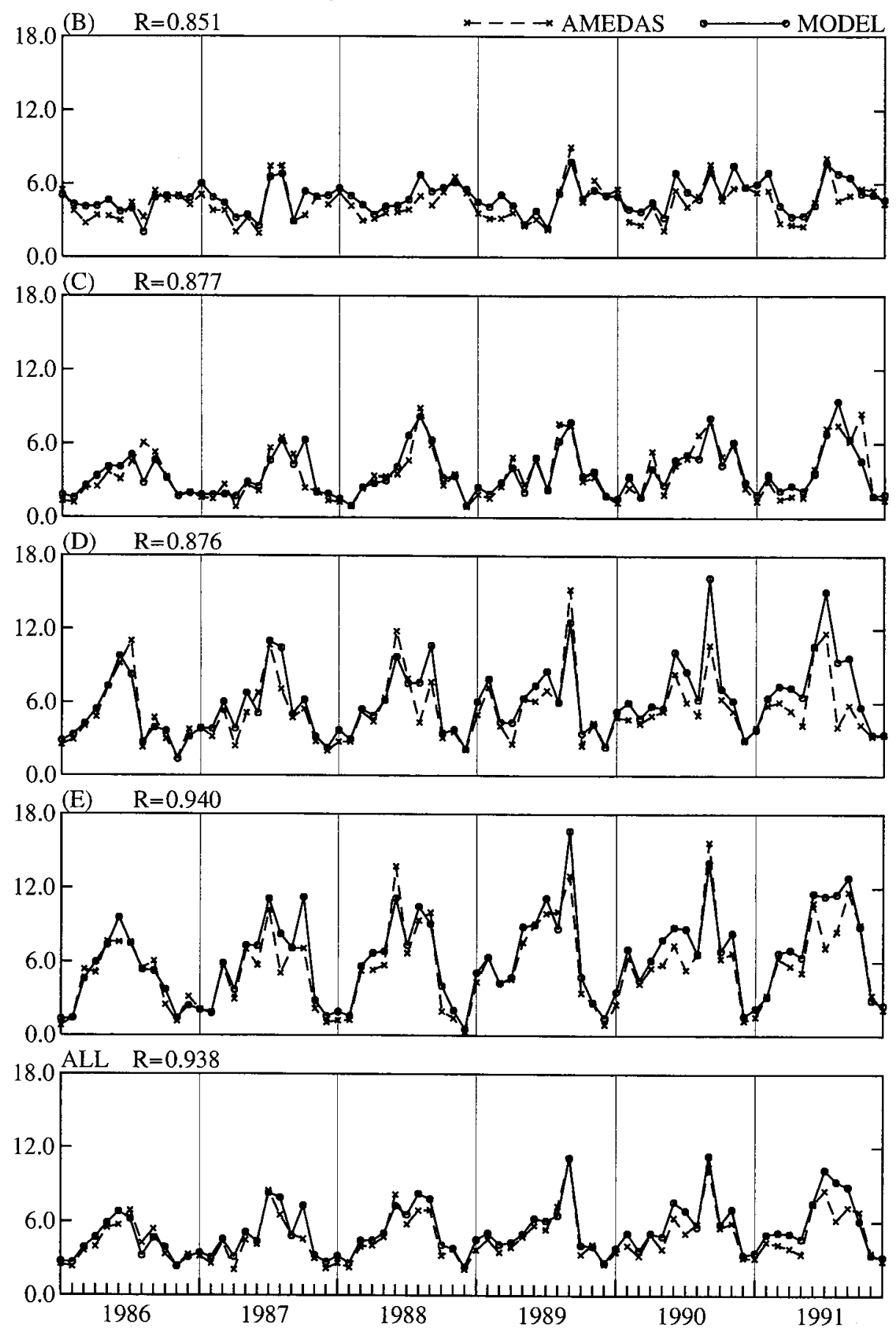

Fig. 9. The comparison of the model precipitation $\left(\mathrm{mm} \mathrm{day}^{-1}\right)$ with AMeDAS precipitation. The top panel indicates the results for Area B (see Fig. 1), the second for Area C, the third for Area D, and the fourth for Area E. The bottom panel (ALL) indicates the comparison of the four-area mean (the mean over the Japanese Islands). The solid lines with circles are the model values, the dashed lines with $\times$ symbols are the AMeDAS values. Each value is the monthly mean, and $R$ is the value of the correlation coefficient for all monthly mean values of the six years (significant absolute $R$ value is 0.195 at $90 \%$ level, and 0.232 at $95 \%$ level). 
sociated with the interannual variations of each monthly value. Vertical bars indicate the difference of the monthly mean value of the sixyear mean between the model and the AMeDAS. The differences are indicated by the vertical broken or solid bars, with the solid bars indicating the differences that are statistically significant at the $95 \%$ level in the $t$-test $(t$ value of 2.228). All values shown are absolute values, with negative values indicated by the $\times$ symbols. The reproducibilities of the model values for each month are verified in this figure.

In Fig. 10, concerning the mean values over the Japanese Islands, the correlation coefficients indicate generally high values, and the

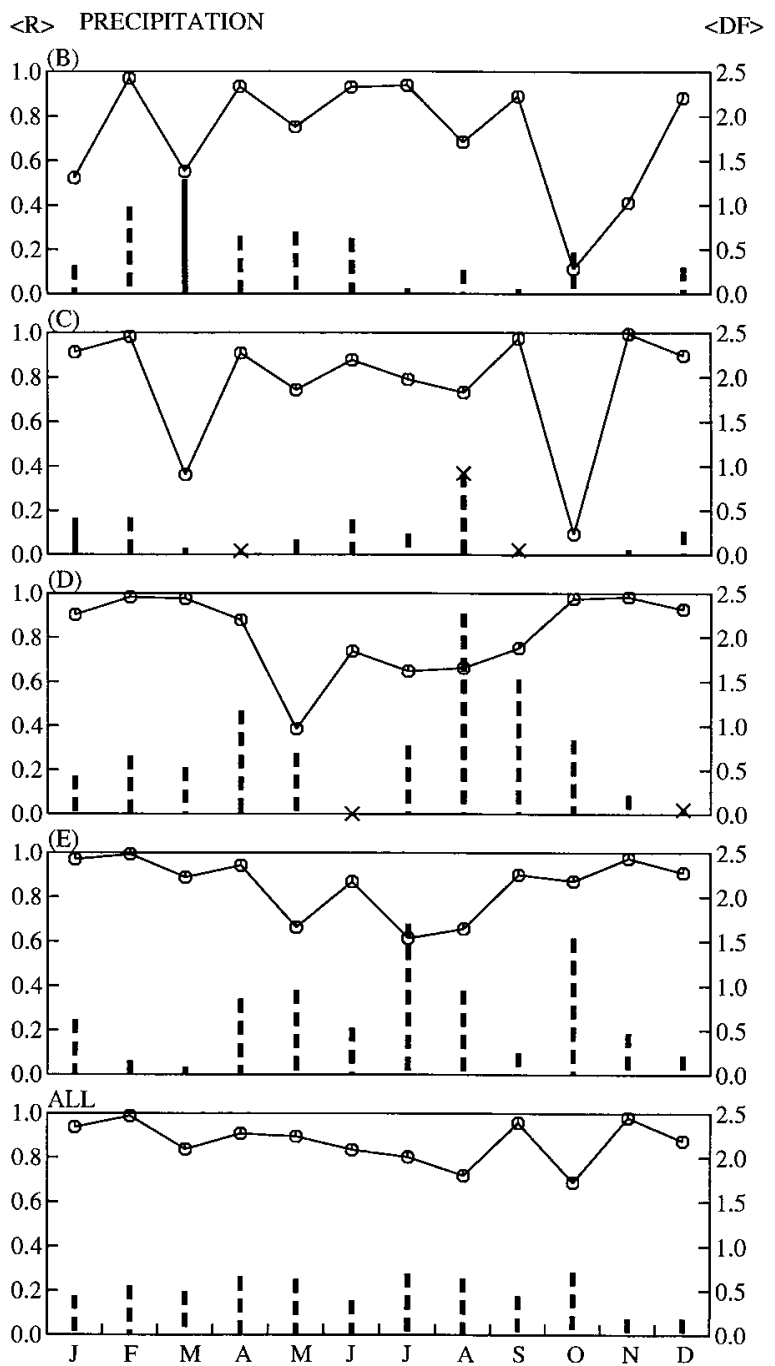

differences between the model and AMeDAS are generally small. Statistically significant differences between the model and the AMeDAS exist only in March in Area B, and in January in Area $\mathrm{C}$ (solid vertical bars).

Although the differences between the model and the AMeDAS are small concerning the mean values over the Japanese Islands, several seasonal and regional features are found in the differences. In Area B, the model precipitation is larger than that of the AMeDAS, especially in February and March. In March, the correlation coefficient also indicates a relatively low value. Although the differences are not large, the correlation coefficients in March in Area C and in autumn in Areas B and $\mathrm{C}$ also indicate low values. Figure 9 indicates a tendency that the model can not reproduce the interannual variations of precipitation in spring and autumn, in Areas B and C. In general, the temporal and spatial variations of atmospheric disturbances are large in spring and autumn in these areas, and accuracy of prediction of the model becomes relatively poor. Therefore, it is considered that the low values of correlation coefficients in Areas B and C are due to the rel-

Fig. 10. The verification of the monthly mean precipitation $\left(\mathrm{mm} \mathrm{day}^{-1}\right)$ performed for each month. The top panel indicates the results for Area B, the second for Area C, the third for Area D, and the fourth for Area E. The bottom panel (ALL) indicates the results for the four-area mean (the mean over the Japanese Islands). Solid lines indicate the correlation coefficients associated with the interannual variations of six years monthly mean values for each month (left-hand ordinate). The value of the significant absolute correlation coefficient is 0.729 at $90 \%$ level, and 0.811 at $95 \%$ level. Vertical broken or solid bars indicate the differences in the monthly mean values of the six-year mean between the model and the AMeDAS (right-hand ordinate; $\mathrm{mm}$ day $^{-1}$ ). The solid bars indicate the differences that are statistically significant. All values shown are absolute values, with negative values indicated by the $x$ symbols. 
atively poor performance of the model in these seasons.

In Areas D and E, the correlation coefficients exhibit relatively low values, and the differences are relatively large in the summer season. The precipitation in the southern part of the Japanese Islands is generally strong in the summer season, with large variations. Although the figure is not shown, the values of summer precipitation calculated by this model over high mountain areas in the Japanese Islands are generally stronger than those of the AMeDAS. These values of precipitation over the high mountain areas represent the orographic rainfall in the summer season, and there is a tendency that the precipitation becomes strong in the model summer. It is considered that these features induce the relatively poor performance of the model during the summer in Areas D and E.

Figures 11 and 12 show the comparisons of the surface air temperatures. The model and AMeDAS surface air temperatures were corrected for elevation above sea level at each data point, assuming a temperature lapse rate of $0.006^{\circ} \mathrm{C} \mathrm{m}^{-1}$. Moreover, to remove the signal of the mean seasonal change, the value of the monthly deviation from the six-year monthly mean AMeDAS values over the Japanese Islands were calculated. The verification was then performed with the use of these values. In Fig. 11 , comparisons of the temporal distributions of the values in each area are indicated. The variation patterns exhibit clear differences between the northern region (Areas B and $\mathrm{C}$ ) and the southern region (Areas D and E) of the Japanese Islands. Although the model values are systematically lower $\left(0.6^{\circ} \mathrm{C}\right.$ for the four-area average) than those of the AMeDAS, the model and AMeDAS data are well correlated in all of the areas. It is concluded that the model can reproduce the features of the seasonal and interannual variations of temperature in each area.

The value of the systematic difference between the model and the AMeDAS depends on the value assigned for the temperature lapse rate used in the correction of the model and AMeDAS temperatures for elevation. While the average elevation of the model grid topography in the Japanese Islands is about $503 \mathrm{~m}$, that of the AMeDAS stations that observe tem- perature is about $156 \mathrm{~m}$. Therefore, the systematic differences between the model and the AMeDAS would be reduced by the use of a temperature lapse rate greater than $0.006^{\circ} \mathrm{C} \mathrm{m}^{-1}$. The model mean temperature over the Japanese Islands is about $0.6^{\circ} \mathrm{C}$ lower than that of the AMeDAS. This difference is reduced to almost zero by the use of a temperature lapse rate of $0.0077^{\circ} \mathrm{C} \mathrm{m}^{-1}$. This lapse rate value is less than the dry adiabatic lapse rate.

In Fig. 12, the correlation coefficients for the interannual variations of the monthly mean temperatures indicate very high correlation in all of the areas. The model accurately reproduces the interannual variations of monthly mean temperatures. Because the model temperature values are systematically lower than those of the AMeDAS, the differences in the sixyear monthly means are indicated as negative values (the $\times$ symbols). Although it must be considered that the differences may depend on the temperature lapse rate used in the correction for topography elevation, some seasonal and regional features are found in the differences.

In May, the model temperatures are significantly lower than the AMeDAS in all of the areas. The model land surface is covered by vegetation, consisting mainly of natural forest. The surface air temperature of the model indicates the air temperature within the forest canopy. On the other hand, those of the AMeDAS are recorded over the observation field, and indicate the air temperature for the open space near the land surface. Figure 13 shows the values of sunshine duration as observed by the AMeDAS (left-hand side) and the downward short-wave radiation calculated by the model (right-hand side). The six-year monthly mean values are indicated. In May, radiation in the Japanese Islands is relatively strong among the months of the year. On the other hand, radiation values in June and July are weaker, due to the rainy season (Bai-u). In May, the vegetation activity becomes active in all of the areas. The vegetation leaf area increases, and the radiation that penetrates into the forest canopy is intercepted. Daytime transpiration is active, which tends to suppress the increase in the leaf temperature. The air temperature within the forest canopy is therefore maintained at a cooler value. The ratio of transpira- 
SURFACE TEMPERATURE $\left({ }^{\circ} \mathrm{C}\right)$
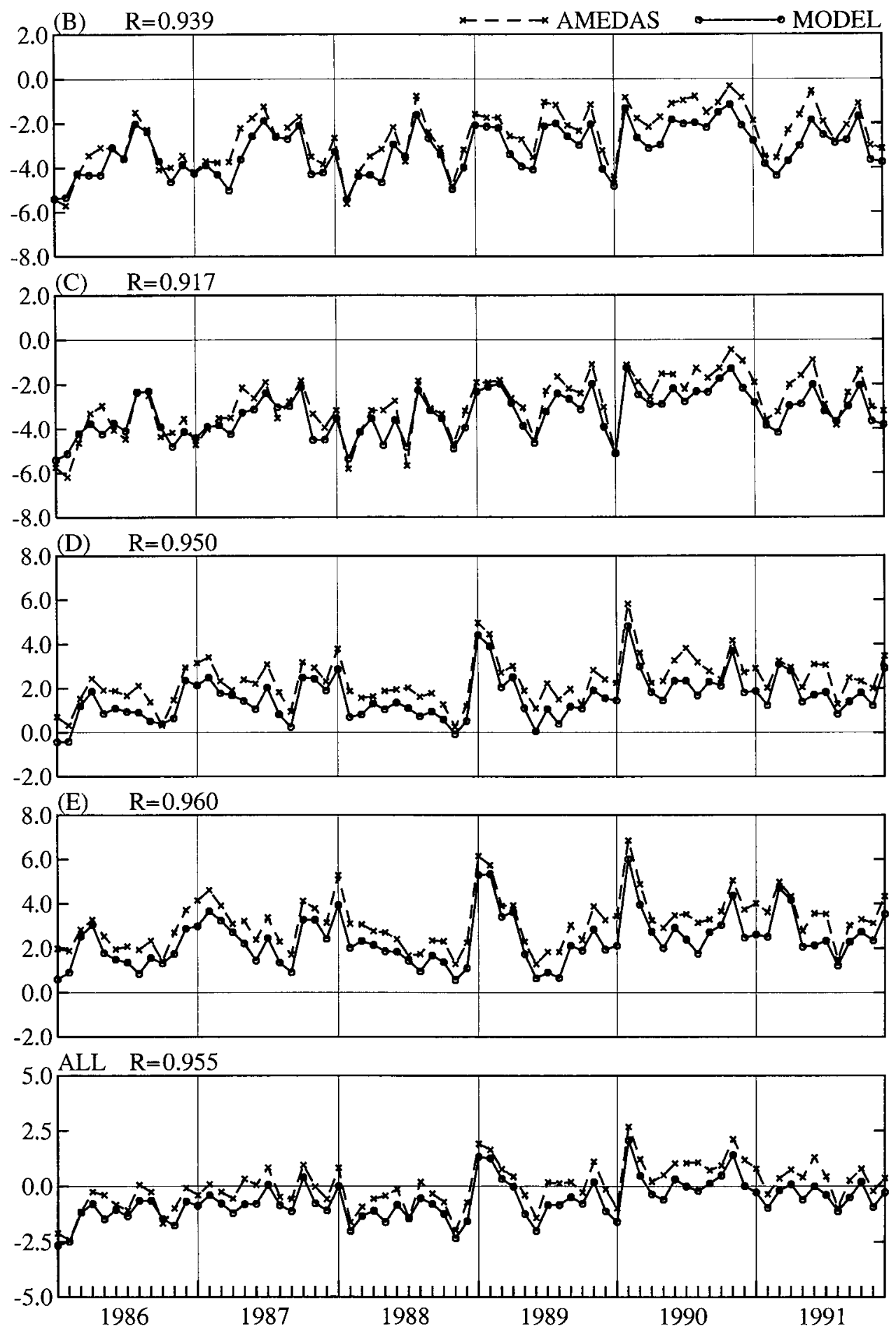

Fig. 11. As in Fig. 9, except for the surface air temperature $\left({ }^{\circ} \mathrm{C}\right.$; values of monthly deviation from the six-year monthly mean AMeDAS values over the Japanese Islands). 
$<$ R $>$ SURFACE TEMPERATURE
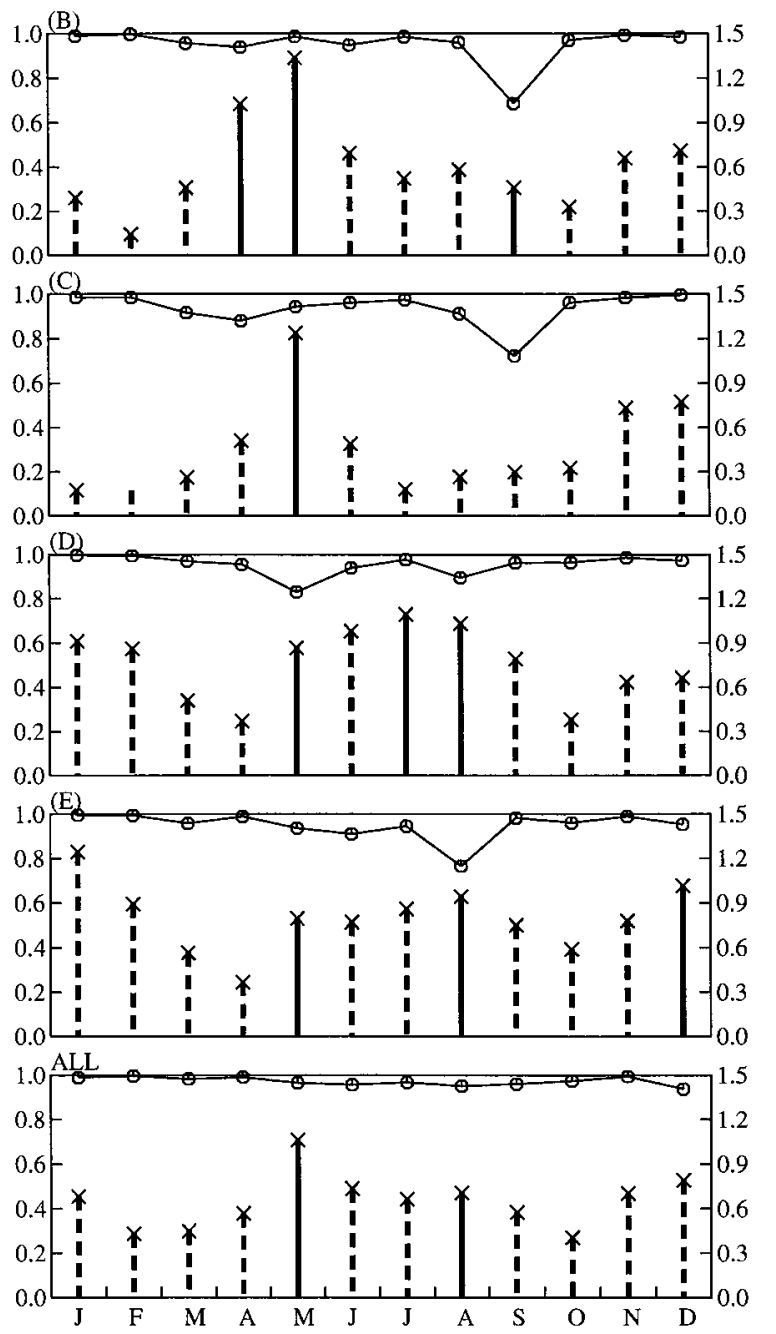

Fig. 12. As in Fig. 10, except for the surface air temperature $\left({ }^{\circ} \mathrm{C}\right.$; values of monthly deviation from the six-year monthly mean AMeDAS values over the Japanese Islands).

tion by vegetation, to the evapotranspiration from the land surface, is bigger during the active vegetation season. Therefore, the control of land surface temperatures by vegetation activity is very effective. It is therefore considered that these vegetation processes induce the difference between the model surface air temperature and that of the AMeDAS.

In Fig. 12, the April temperature difference in Area B is significantly large. In Fig. 10, it was shown that the model precipitation in Area
B was greater than the AMeDAS in February and March. Therefore, the possibility exists that the model snow is greater than that on the observational field, and model snowmelt in the spring is delayed. Although it is necessary to consider that the speed of the snowmelt differs between an open space environment such as an AMeDAS point and a forest environment, this delay in the model snowmelt produces lower model temperatures in April in Area B.

While the summer temperature differences are small in the northern part of the Japanese Islands, those in the southern part of the Japanese Islands (Areas D and E) indicate generally large values. In the southern areas, the radiation intensity is relatively strong, and temperatures are higher in the summer season. Therefore, it is considered that the same factors that resulted in the large May differences are also those that cause the large difference in the summer season in the southern areas. There is, however, another possible reason for these large summer temperature differences in these areas. In Fig. 6, it was shown that the cloudiness in the southern part of the Japanese Islands was relatively large in the summer season. Figure 10 showed a tendency for the model summer precipitation in Areas D and E to become greater than that of the AMeDAS. In Fig. 13 , although the values of downward shortwave radiation can not be directly compared to the values of sunshine duration, there is a tendency for relatively weaker summer radiation in the model for Areas D and E when compared with the values of sunshine duration of the AMeDAS, especially in August. For these reasons, it is possible that the model radiation values in Areas D and E are weaker than the actual values in the summer season. It is thought that this weaker model radiation becomes the source for the lower model summer temperatures in the southern part of the Japanese Islands.

In Areas $\mathrm{D}$ and $\mathrm{E}$, the temperature differences in the winter season are also relatively large. The values of winter cloudiness in the model are small in the southern part of the Japanese Islands (figure not shown), and the values of winter precipitation are also small in these areas, especially in Area E (see Fig. 9). In Fig. 10, it was shown that the differences in winter precipitation between the model and 

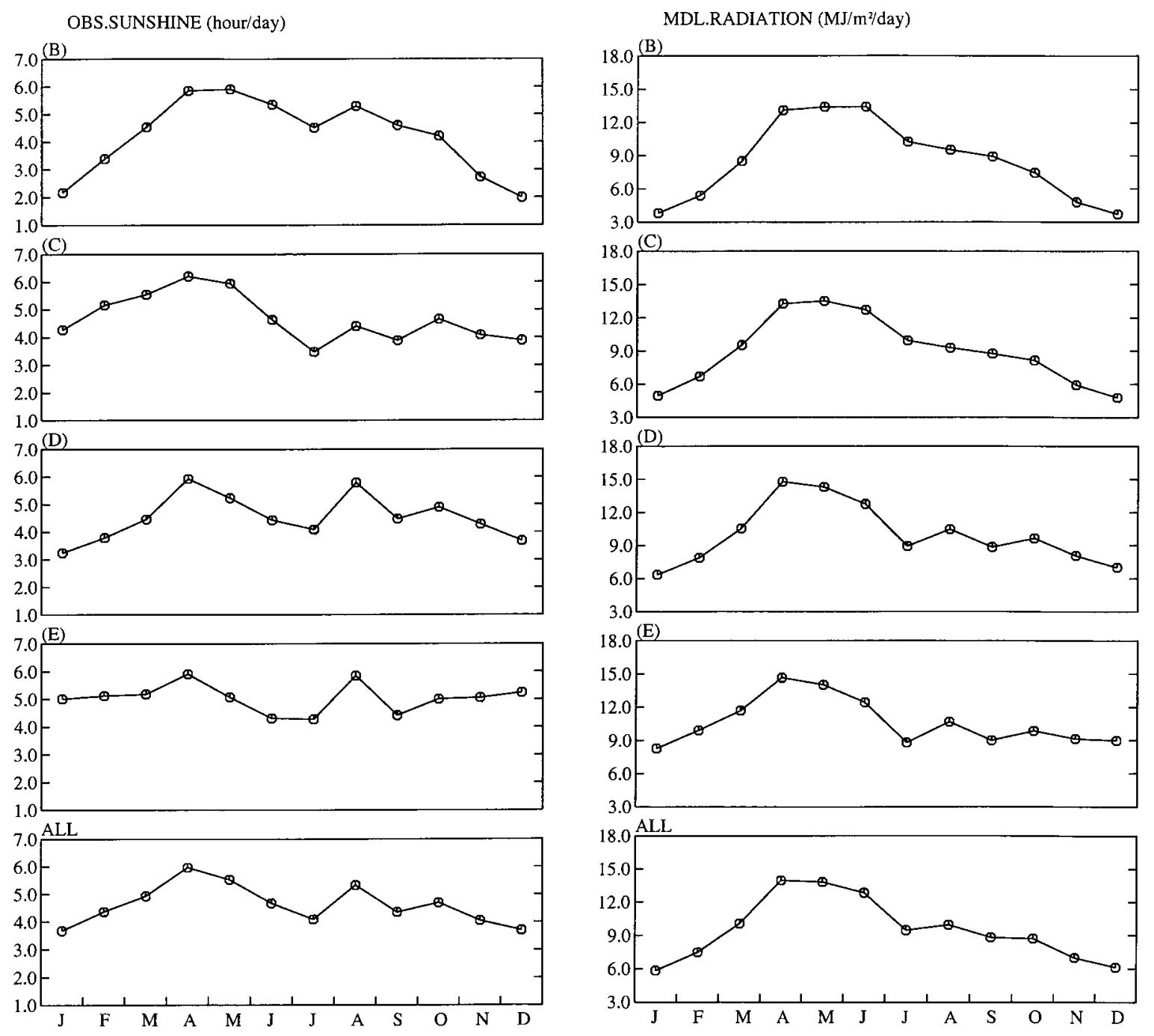

Fig. 13. The duration of sunshine (hour day ${ }^{-1}$ ) observed by the AMeDAS (left-hand side) and the downward short-wave radiation $\left(\mathrm{MJ} \mathrm{m}^{-2}\right.$ day $^{-1}$ ) calculated by the model (right-hand side). The sixyear monthly mean values are indicated. The top panels indicate the values in Area B, the second in Area C, the third in Area D, and the fourth in Area E. The bottom panels (ALL) indicate the four-area mean (the mean over the Japanese Islands) values.

the AMeDAS were also small in Areas D and E. Therefore it is considered that in the model, reduced radiation due to an excess of cloud amounts does not exist in these areas in the winter season. In these areas, the vegetation type of evergreen forest covers a relatively wide region. The winter radiation values are relatively strong, especially in Area E. Although vegetation is not very active when compared with that in the summer season, there is the possibility that the factors related to large temperature differences in May could also be the cause of the relatively large differences in the winter season in the southern part of the Japanese Islands. In general, there is less cloudiness in Area E in winter. Therefore, another possibility exists, namely that the effect of radiational cooling at the land surface is too strong in the model.

In the discussions described above, there were several possible reasons for the discrepancy between the model temperature and the 
AMeDAS temperature. The natural vegetation in the Japanese Islands is mainly classified as forest. Therefore, as already mentioned in the analysis of the 850 -hPa level summer temperature, observed data over a wide area of a natural forest environment are necessary for more accurate verification of the model surface air temperature.

Figures 14 and 15 show the comparisons of the downward short-wave radiation (SR) calculated by the model versus the duration of sunshine (DS) observed by the AMeDAS. The values of SR are normalized by the value of solar radiation at the top of the atmosphere. The DS values are normalized by the value of the possible duration of sunshine. Moreover, the comparison is performed with respect to the deviation from the six-year mean value of each variable in each area. As was previously mentioned, although the values of downward shortwave radiation can not be directly compared to the values of sunshine duration, a relative comparison is possible.

Figure 14 indicates the temporal distributions of the comparison of monthly mean values of SR and DS in each area. Although the correlation coefficients in Areas B and D (the areas facing the Sea of Japan) are somewhat less than those in the Areas $\mathrm{C}$ and $\mathrm{E}$, the model reproduces the features of the seasonal and interannual variations of the radiation reasonably well in each area of the Japanese Islands.

Figure 15 indicates the correlation coefficients between SR and DS for the interannual variations of six years monthly values in each area. In general, weak correlation is found in the cold season in the northern part of the Japanese Islands. On the other hand, there is a tendency for relatively weaker correlation in the warm season in the southern part of the Japanese Islands, especially in Area E. Although the values of the correlation coefficient of cold season precipitation in the northern part of the Japanese Islands are not generally small, the seasonal features of the radiation correlation coefficients correspond with those of the precipitation (see Fig. 10). It is considered that the reproducibility of radiation in the model is closely associated with the reproducibility of the model precipitation.

The April coefficient values exhibited in Fig. 15 have extremely small values in all of the areas. The model performance with respect to the precipitation and the temperature in April are not necessarily poor. The extremely small values of the coefficients in April could result from the differences found between the SR and DS. Namely, while the SR and DS values are almost the same in 1988 and 1989, the SR values are smaller in 1986 and 1987, and larger in 1990 and 1991, than the DS values. The physical reason for the extremely small April coefficient values could not be clarified by the present investigation.

\section{Summary and discussion}

Verification of local climatic features produced by the regional climate model JSMBAIM was performed. The model data used in the verification were the results of a six-year period integration calculated by the JSMBAIM. In the time integration of the JSMBAIM, the spectral boundary coupling (SBC) method was used, in addition to the conventional boundary relaxation method.

Comparisons of the model results with the analysis data (JANAL) were performed with respect to geopotential heights, temperatures, and winds at the $850-\mathrm{hPa}$ and $500-\mathrm{hPa}$ levels. Statistically significant differences appeared mainly in the summer temperature field, and in the summer and winter wind fields.

The model summer temperatures at the 850$\mathrm{hPa}$ level were significantly lower than the JANAL temperatures around the high mountain area in the northern part of the model domain. The elevations of the JSM-BAIM topography were higher than those of the JANAL field in the mountain regions. The temperature of the JSM-BAIM at the $850-\mathrm{hPa}$ level was strongly influenced by the near land surface temperature in the high mountain regions. It was concluded that the model evapotranspiration from the land surface was large, and the increase in the land surface temperature was suppressed. Over the southern part of the Japanese Islands, there was the possibility that reduced radiation at the land surface could be another cause of the systematic lower land surface temperatures in the model. In the summer, these lower model land surface temperatures cause the model $850-\mathrm{hPa}$ level temperatures around high mountain areas to be cooler than those of the JANAL. 
OBS.SUNSHINE<>MDL.RADIATION
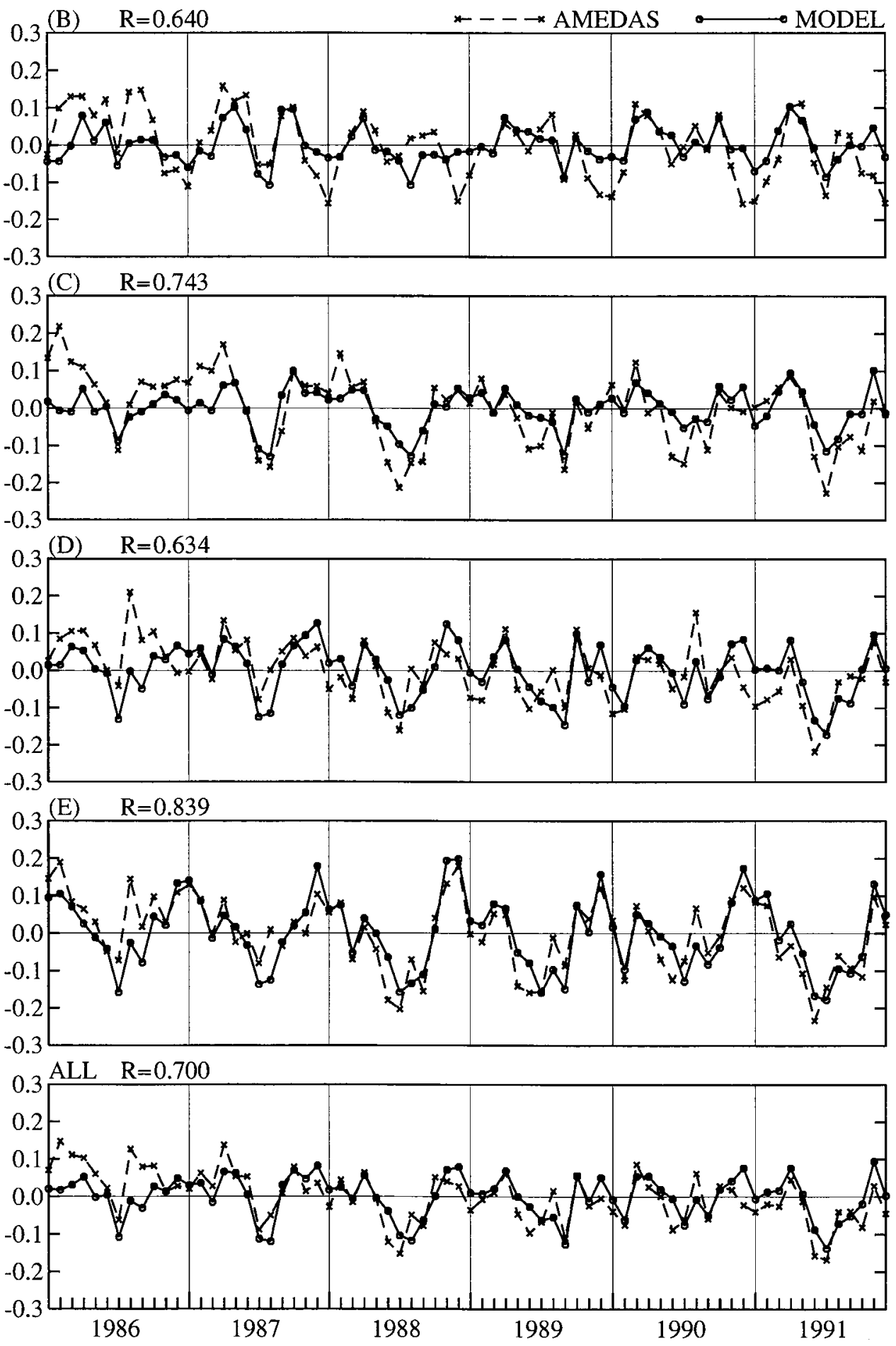

Fig. 14. As in Fig. 9, except for the downward short-wave radiation (solid lines with circles) calculated by the model (SR), and the duration of sunshine (dashed lines with $\times$ symbols) observed by the AMeDAS (DS). The SR values are normalized by the solar radiation at the top of the atmosphere, and the DS values are normalized by the possible duration of sunshine. The values of the deviation from the six-year mean value of each variable in each area are indicated. 
$<$ R $>$ OBS.SUNSHINE $>$ MDL.RADIATION
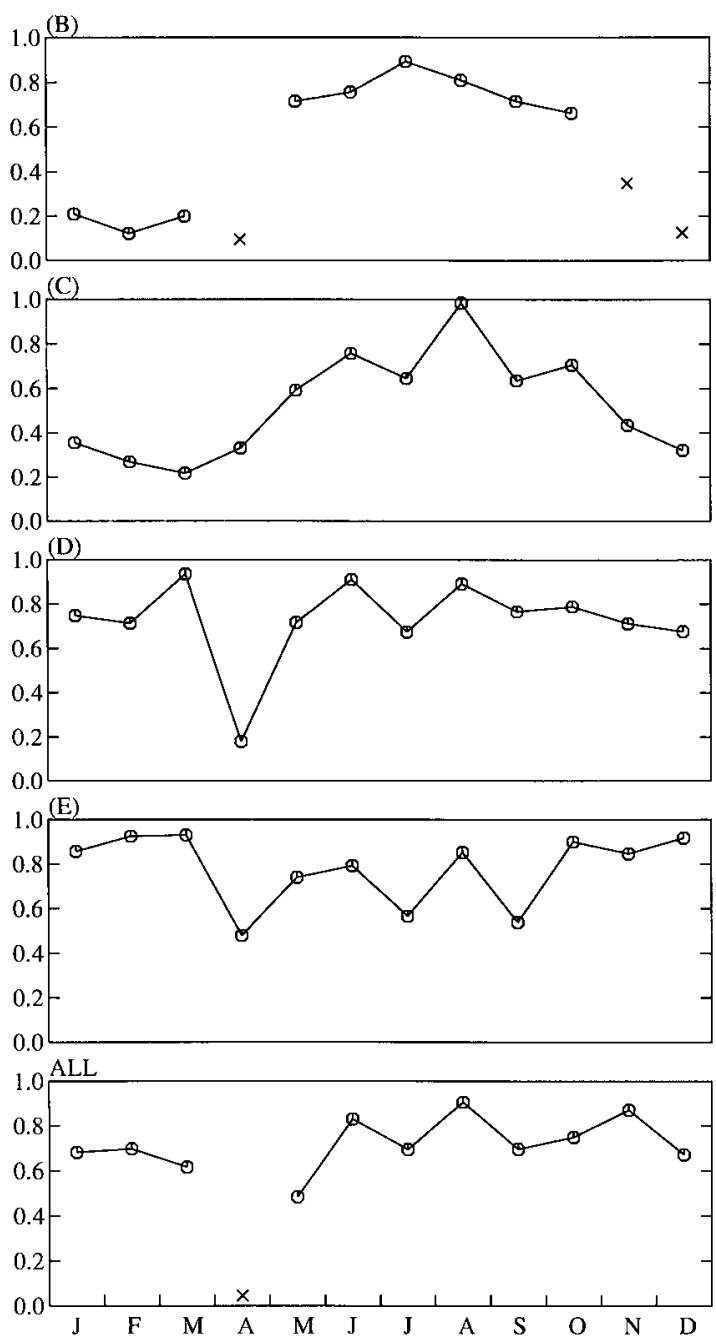

Fig. 15. As in Fig. 10, except for the downward short-wave radiation calculated by the model (SR) and the duration of sunshine observed by the AMeDAS (DS). The monthly values of the correlation coefficient are indicated. All values shown are absolute values, with negative values indicated by the $\times$ symbols.

The model summer temperatures at the 850$\mathrm{hPa}$ level were significantly cooler and those at the $500-\mathrm{hPa}$ level were significantly warmer than those of the JANAL over the ocean area in the southern part of the model domain. This may have resulted from the possibility of more model cloudiness over the ocean area in the southern part of the model domain than may have occurred in the JANAL field. It was considered that the overall balance of heating rates by the short-wave and long-wave radiation associated with the cloud, and the effect of the condensation process of water vapor related to precipitation events, influenced the model temperatures in the middle and lower atmospheric layers. These effects, in turn, induced the temperature differences between the model and the JANAL at the $850-\mathrm{hPa}$ and $500-\mathrm{hPa}$ levels over the ocean area in the southern part of the model domain.

It was concluded that the statistically significant differences in the wind field were mainly due to the difference in topography between the model field and the JANAL field, especially when interacting with the strong wind flow of the winter season. The JSM-BAIM field has a more realistic topography than that of the JANAL field. Therefore, it was considered that the wind field calculated by the JSM-BAIM indicated a more realistic pattern than that of the JANAL.

Sasaki et al. (2000) concluded that when both the SBC method and the boundary relaxation method were used together, the overall error in the model domain was reduced. As a result of the use of the SBC method, along with the conventional boundary relaxation method in the present study, it was considered that largescale differences between the model results and the JANAL were reduced in each data field, both at the $850-\mathrm{hPa}$ and the $500-\mathrm{hPa}$ levels.

Comparisons of the model results with the AMeDAS data were performed with respect to the variables of precipitation, surface air temperature, and radiation at the land surface over the Japanese Islands. The region of the Japanese Islands was divided into four areas according to regional climate features, and data were examined in each area.

Although the model surface air temperatures were systematically lower than the AMeDAS, the model reasonably well reproduced the features of the seasonal and interannual variations of each variable in each area. There were, however, several seasonal and regional features found in the differences between the model results and the AMeDAS data.

Concerning the precipitation, the differences between the model results and the AMeDAS 
data were relatively large in the warm season in the southern part of the Japanese Islands. It was considered that the summer precipitation calculated by this model over high mountain areas in the southern part of the Japanese Islands was stronger than that of the AMeDAS.

Concerning the surface air temperature, the differences in the southern part of the Japanese Islands were relatively larger than those in the northern part of the Japanese Islands. In May in particular, the model values were significantly lower than the AMeDAS in all of the areas. It was concluded that the causes of the significant differences were mainly the effect of the vegetation process in the model, and a reduced model radiation in the summer in the southern part of the Japanese Islands. It was also considered that in the southern part of the Japanese Islands, the effect of radiational cooling at the land surface was a reason for the systematic low winter temperatures of the model.

Concerning the radiation, the seasonal features of the correlation coefficients between SR and DS for the interannual variations of monthly values in each area, corresponded with those of the precipitation. It was considered that the reproducibility of radiation in the model was closely associated with the reproducibility of model precipitation.

The transpiration by vegetation at the land surface is very important. The ratio of transpiration by vegetation to the evapotranspiration from the land surface is large, especially during the active vegetation season. The control of the land surface temperature by vegetation activity is very effective. Other physical processes at the land surface also differ from an open space environment to a natural forest environment. More data observed over a wide area of natural vegetation (especially in a forest environment) are necessary for a more accurate verification of the near land surface air temperature of the model.

Observed data over the ocean area are limited in both time and space. Therefore, the differences in resolution and physical process between the model field and the analysis field directly resulted in the differences between the model and the analysis. It has become necessary for the verification of the model to obtain a larger observed dataset over the ocean area in both time and space. For this purpose, satellite data and other assimilation data will be useful for the verification of the model results over ocean areas.

As already mentioned in the analysis of Fig. 10, the summer precipitation of this model around high mountain areas was generally stronger than that of the AMeDAS data. Precipitation during the summer season has a tendency to be locally strong, especially in mountainous areas. Observing stations are, however, not usually located in mountainous areas. Therefore, to achieve a more accurate verification of the model's local precipitation, a higher density of observed precipitation is necessary, especially in high mountain areas.

In the present study, the performance of the JSM-BAIM was confirmed concerning the reproducibility of the main atmospheric variables, and that of the seasonal and interannual variations of the principal elements (that is, precipitation, temperature, and radiation) which influence the heat, water, and carbon dioxide balances at the land surface through vegetation activity. Regional climate models used to investigate the mechanisms of the interactions between the atmosphere and the terrestrial biosphere are required to satisfy certain conditions. That is, the models must accurately reproduce the temporal and spatial climatic features of these principal elements in as much detail as possible. It was found that the JSM-BAIM, with the use of the spectral boundary coupling (SBC) method in a long time integration, had sufficient accuracy to allow for investigations of the interaction mechanisms between the terrestrial ecosystems and climate; temporally at least on the level of the seasonal and interannual variations, and spatially at least on the level of the climatic classification of the Japanese Islands. There is, however, the necessity for further verification using observed data, especially with respect to the near land surface air temperature in a natural vegetation environment, and the atmospheric variables over the ocean.

\section{Acknowledgements}

The authors thank two anonymous reviewers for their many helpful suggestions and comments for improving this manuscript. This research was partially supported by the Global Environment Research Fund of the Environ- 
ment Agency, and partially by the Funds for the Promotion of Surveys and Research in Earth Science and Technologies and Ocean Development of the Science and Technology Agency. The model computations were performed on the HITAC-S3800 computer.

\section{References}

Davies, H.C., 1976: A lateral boundary formulation for multilevel prediction models. Quart. J. Roy. Meteor. Soc., 102, 405-418.

Dickinson, R.E., R.M. Errico, F. Giorgi and G.T. Bates, 1989: A regional climate model for the western United States. Clim. Change, 15, 383422.

Giorgi, F., 1990: On the simulation of regional climate using a limited area model nested in a general circulation model. J. Climate, 3, 941963.

-, Y. Huang, K. Nishizawa and C. Fu, 1999: A seasonal cycle simulation over eastern Asia and its sensitivity to radiative transfer and surface processes. J. Geophys. Res., 104, 64036424.

IPCC, 1996: Climate Change 1995: The Science of Climate Change. J.T. Houghton, L.G. Meira Filho, B.A. Callender, N. Harris, A. Kattenberg and K. Maskell (eds.), Cambridge University Press, New York.

Japan Meteorological Agency, 1994: The observation of carbon dioxide in air over the sea and surface sea water in the western North Pacific Ocean and estimation of air/sea flux. J. Meteor. Res., 46, 63-69. (in Japanese)

- 1996: Report of the Numerical Prediction Division, 42. (in Japanese)

Kida, H., T. Koide, H. Sasaki and M. Chiba, 1991: A new approach for coupling a limited area model to a GCM for regional climate simulations. J. Meteor. Soc. Japan, 69, 723-728.

Kidson, J.W. and C.S. Thompson, 1998: Comparison of statistical and model-based downscaling techniques for estimating local climate variations. J. Climate, 11, 735-753.

Lacis, A.A. and J.E. Hansen, 1974: A parameterization for the absorption of solar radiation in the earth's atmosphere. J. Atmos. Sci., 31, 118-133.

Lean, J. and P.R. Rowntree, 1997: Understanding the sensitivity of a GCM simulation of Amazonian deforestation to the specification of vege- tation and soil characteristics. J. Climate, 10, 1216-1235.

Mabuchi, K., Y. Sato, H. Kida, N. Saigusa and T. Oikawa, 1997: A Biosphere-Atmosphere Interaction Model (BAIM) and its primary verifications using grassland data. Papers in Meteor. and Geophys., 47, 115-140. , — - and 2000: Numerical study of the relationships between climate and the carbon dioxide cycle on a regional scale. J. Meteor. Soc. Japan, 78, 25-46.

Mellor, G.L. and T. Yamada, 1974: A hierarchy of turbulent closure models for planetary boundary layers. J. Atmos. Sci., 31, 1791-1806.

Nakazawa, T., S. Morimoto, S. Aoki and M. Tanaka, 1993: Time and space variations of the carbon isotopic ratio of tropospheric carbon dioxide over Japan. Tellus, 45B, 258-274.

Noguer, M., R.G. Jones and J. Murphy, 1998: Sources of systematic errors in the climatology of a nested regional climate model (RCM) over Europe. Clim. Dyn., 14, 691-712.

Rayner, N.A., E.B. Horton, D.E. Parker, C.K. Folland and R.B. Hackett, 1996: Version 2.2 of the Global Sea-Ice and Sea Surface Temperature data set, 1903-1994. CRTN 74, Hadley Centre for Climate Prediction and Research, Meteorological Office, London Road, Bracknell, Berkshire, RG12 2SY.

Sasaki, H., H. Kida, T. Koide and M. Chiba, 1995: The performance of long-term integrations of a limited area model with the spectral boundary coupling method. J. Meteor. Soc. Japan, 73, 165-181.

— Y. Sato, K. Adachi and H. Kida, 2000: Performance and evaluation of the MRI regional climate model with the spectral boundary coupling method. J. Meteor. Soc. Japan, 78, 477489.

Seth, A. and F. Giorgi, 1998: The effects of domain choice on summer precipitation simulation and sensitivity in a regional climate model. J. Climate, 11, 2698-2712.

Small, E.E., F. Giorgi and L.C. Sloan, 1999: Regional climate model simulation of precipitation in central Asia: Mean and interannual variability. J. Geophys. Res., 104, 6563-6582.

Sugi, M., K. Kuma, K. Tada, K. Tamiya, N. Hasegawa, T. Iwasaki, S. Yamada and T. Kitade, 1990: Description and performance of the JMA operational global spectral model (JMAGSM89). Geophys. Mag., 43, 105-130. 